\title{
Estimating and Testing Process Precision with Presence of Gauge Measurement Errors
}

\author{
W. L. PEARN ${ }^{1, *}$ and MOU-YUAN LIAO ${ }^{2}$ \\ ${ }^{1}$ Department of Industrial Engineering and Management, National Chiao Tung University, \\ Taiwan, R.O.C. \\ ${ }^{2}$ Department of Finance and Banking, Yuanpei University, 306 Yuan Pei Street, Hsinchu, \\ Taiwan, R.O.C.
}

\begin{abstract}
Process capability indices have been widely used in the manufacturing industry. Those capability indices, quantifying process potential and performance, are important for any successful quality improvement activities and quality program implementation. Because of the simplicity and easy of understanding, the precision index $C_{p}$ has gained its popularity for measuring process consistency. However, the quality of data on the process characteristics relies very much on the gauge measurement. Conclusions about capability of the process just only based on the single numerical value of the index are not reliable. In this paper, we not only conduct the performance of the index $C_{p}$ with gauge measurement errors, but also present adjusted confidence interval bounds and critical values for capability testing purpose of $\mathrm{C}_{\mathrm{p}}$ with unavoidable measurement errors. Our research would help practitioners to determine whether the factory processes meet the capability requirement, and make more reliable decisions.
\end{abstract}

Key words: confidence interval, critical value, gauge measurement error, process capability analysis.

\section{Introduction}

Process capability indices, which establish the relationships between the actual process performance and the manufacturing specifications, have been the focus of recent research in quality assurance and process capability analysis. Those capability indices, quantifying process potential and performance, are important for any successful quality improvement activities and quality program implementation. The first, and the original, process capability index was $\mathrm{C}_{\mathrm{p}}$, which was introduced outside of Japan by Juran et al. (1974), but did not gain considerable acceptance until the early 1980s. It is defined as

\footnotetext{
${ }^{*}$ Author for correspondence: W.L. Pearn, Department of Industrial Engineering and Management, National Chiao Tung University, 1001 Ta Hsueh Road, Hsinchu, Taiwan, R.O.C.
} 


$$
\mathrm{C}_{\mathrm{p}}=\frac{\mathrm{USL}-\mathrm{LSL}}{6 \sigma}
$$

where LSL is the lower specification limit, USL is the upper specification limit, and $\sigma$ is the process standard deviation. The numerator of $\mathrm{C}_{\mathrm{p}}$ gives the size of the range over which the process measurements can vary, and the denominator gives the size of the range over which the process is actually varying. Obviously, it is desirable to have a $C_{p}$ as large as possible. Small values of $C_{p}$ would not be acceptable, since this indicates that the natural range of variation of the process does not fit within the tolerance band. Under the assumption of that process data are normal, independent, and in control, Kocherlakota (1992) developed a general guideline for the percentage $\mathrm{NC}$ (non-conforming units) associated with $\mathrm{C}_{\mathrm{p}}$, assuming that the process is perfectly centered at the midpoint of the specification range (see Table I). Mizuno (1988) presented detailed criteria for $\mathrm{C}_{\mathrm{p}}$, which had been widely used in U.S. industries. These criteria provide guidelines for management response to specific ranges of $C_{p}$ values (see Table II).

Table I. Minimum proportion NC associated with various values of $\mathrm{C}_{\mathrm{p}}$

\begin{tabular}{ccl}
\hline $\begin{array}{l}\text { Amount of process data } \\
\text { within specification range }\end{array}$ & $\mathrm{C}_{\mathrm{p}}$ & Minimum \% NC \\
\hline $6 \sigma$ & 1.00 & $0.27 \times 10^{-2}$ \\
$8 \sigma$ & 1.33 & $0.6334 \times 10^{-4}$ \\
$10 \sigma$ & 1.67 & $0.5733 \times 10^{-6}$ \\
$12 \sigma$ & 2.00 & $0.1973 \times 10^{-8}$ \\
\hline
\end{tabular}

Table II. Appropriate responses to $\mathrm{C}_{\mathrm{p}}$ values

\begin{tabular}{lll}
\hline Process capability & Assessment & Response \\
\hline $1.33 \leq \mathrm{C}_{\mathrm{p}}$ & Pass & $\begin{array}{l}\text { Sufficient to inspect at start of } \\
\text { operations. Can consider speeding up } \\
\text { process or otherwise increasing }\end{array}$ \\
$1 \leq \mathrm{C}_{\mathrm{p}} \leq 1.33$ & Needs watching & $\begin{array}{l}\text { load Danger of producing defects. } \\
\text { Needs watching } \\
\mathrm{C}_{\mathrm{p}}<1\end{array}$ \\
& Fail & $\begin{array}{l}\text { Need to consider changing procedures, } \\
\text { changing equipment and changing } \\
\text { tolerance. Inspect total output }\end{array}$ \\
& &
\end{tabular}

Moreover, Montgomery (2000) has recommended some minimum values for $\mathrm{C}_{\mathrm{p}}$. That is, 1.33 for existing processes, 1.50 for new processes. For product characteristics that are essential to safety, strength or performance 
features, Kotz and Johnson (1993) recommend minimum values of 1.50 for existing processes and 1.67 for new processes. Because of the simplicity and easy of understanding, $\mathrm{C}_{\mathrm{p}}$ has gained the most popularity in the manufacturing industry. Using the index $\mathrm{C}_{\mathrm{p}}$, the practitioners can evaluate their process precision.

However, no measurement is free from error or uncertainty even though it may be conducted with the aid of highly sophisticated measuring instruments. Montgomery and Runger (1993) pointed out that the quality of data on the process characteristics relies very much on the gauge. Any variation in the measurement process has a direct impact on the ability to make sound judgment about the manufacturing process. Conclusions about capability of the process just only based on the single numerical value of the index are not reliable. Analyzing the effects of measurement errors on process capability indices, Mittag (1997) and Levinson (1995) provided some very definitive techniques for quantifying the percentage error in process capability indices estimation in the presence of measurement errors. In this paper, we not only conduct the behavior of the widely used process capability index $C_{p}$ with gauge measurement errors, but also present some statistical analysis research in order to establish reliable confidence interval bounds and critical values for estimation and testing hypothesis of $\mathrm{C}_{\mathrm{p}}$ with unavoidable measurement errors. In Section 2, we introduce the true process capability derives from the empirical process capability. In Section 3, we discuss the expected value, the variance, and the MSE (mean square error) of the estimator of estimating $\mathrm{C}_{\mathrm{p}}$ with gauge measurement errors. In Sections 4 and 5, because of measurement errors, we show that the confidence intervals do not maintain the stated confidence coefficient, and when we do a statistical testing, both the $\alpha$-risk and the power of the test may decrease substantially. Since the power becomes slightly, a great deal of extra cost will accompany the results that quantities of qualified product units are incorrectly rejected by the customers, or renewed to the producers. To have proper confidence coefficients and to improve the power of the test with appropriate $\alpha$-risk, adjusted confidence interval bounds and critical values are proposed in Section 6. Finally, we have some conclusions in Section 7.

\section{Process Capability with Gauge Measurement Errors}

Gauge repeatability and reproducibility (GR\&R) studies focus on quantifying the measurement errors. Common approaches to GR\&R studies, such as the Range method (Montgomery and Runger, 1993) and the ANOVA method (Mandel, 1972; Montgomery and Runger, 1993) assume that the distribution of the measurement errors is normally distributed with a mean error of zero. Suppose that the measurement errors are described by 
a random variable $\mathrm{M} \sim \operatorname{Normal}\left(0, \sigma_{\mathrm{M}}^{2}\right)$, Montgomery (Montgomery and Runger, 1993) presents the gauge capability by

$$
\lambda=\frac{6 \sigma_{\mathrm{M}}}{\mathrm{USL}-\mathrm{LSL}} \times 100 \% .
$$

For the measurement system to be deemed acceptable, the variability in the measurements due to the measurement system must be less than a predetermined percentage of the engineering tolerance. The Automotive Industry Action Group recommends some guidelines for gauge acceptance (see Table III),

Table III. Guidelines for gauge capabilities

\begin{tabular}{ll}
\hline Gauge capability & Result \\
\hline$\lambda<10 \%$ & Gauge system OK \\
$10 \%<\lambda<30 \%$ & $\begin{array}{l}\text { May be acceptable based on importance of application, } \\
\text { cost of gauge, cost of repair, and so on }\end{array}$ \\
$30 \%<\lambda$ & $\begin{array}{l}\text { Gauge system needs improvement; make every effort } \\
\text { to identify the problems and have them corrected }\end{array}$ \\
\hline
\end{tabular}

Considering the process capability in the measurement error system, we denote $\mathrm{X} \sim$ Normal $\left(\mu, \sigma^{2}\right)$ the relevant quality characteristic of a manufacturing process. Because of measurement errors, the observed variable $\mathrm{Y}$ $\sim$ Normal $\left(\mu_{\mathrm{Y}}=\mu, \sigma_{\mathrm{Y}}^{2}=\sigma^{2}+\sigma_{\mathrm{M}}^{2}\right)$ is measured by the assumption that $\mathrm{X}$ and $\mathrm{M}$ are stochastically independent, instead of measuring the true variable $\mathrm{X}$. The empirical process capability index $\mathrm{C}_{\mathrm{P}}^{\mathrm{Y}}$ is obtained after substituting $\sigma_{\mathrm{Y}}$ for $\sigma$, and we have the relationship between the true process capability $\mathrm{C}_{\mathrm{p}}$ and the empirical process capability $\mathrm{C}_{\mathrm{P}}^{\mathrm{Y}}$ as

$$
C_{p}^{Y}=\frac{C_{p}}{\sqrt{1+\lambda^{2} C_{p}^{2}}} .
$$

Since the variation of data we observed is larger than the variation of the original data, the denominator of the index $\mathrm{C}_{\mathrm{p}}$ becomes larger, and we will understate the true capability of the process if we calculate process capability index with variable Y. In Table IV, we list some process capabilities with $\lambda=0.05(0.05) 0.50$ for various true process capability index $\mathrm{C}_{p}=0.50,1.00,1.33,1.50,1.67,2.00$, and 2.50 . It is obviously that the gauge becomes more important as the true capability improves (Levinson, 1995). If $\lambda=0.50(50 \%), C_{\mathrm{P}}^{Y}=0.49$ with the true process capability $C_{p}=0.50$, and $\mathrm{C}_{\mathrm{P}}^{\mathrm{Y}}=1.56$ with the true process capability $\mathrm{C}_{\mathrm{p}}=2.50$. Substituting a perfect measuring instrument will help much for processes with higher capability. 
Table IV. Process capability with $\lambda=0.05(0.05) 0.50$ for various $\mathrm{C}_{\mathrm{p}}$

\begin{tabular}{lllllllllll}
\hline & \multicolumn{10}{c}{$\lambda$} \\
\cline { 2 - 11 } $\mathrm{C}_{\mathrm{p}}$ & 0.05 & 0.10 & 0.15 & 0.20 & 0.25 & 0.30 & 0.35 & 0.40 & 0.45 & 0.50 \\
\hline 0.50 & 0.50 & 0.50 & 0.50 & 0.50 & 0.50 & 0.49 & 0.49 & 0.49 & 0.49 & 0.49 \\
1.00 & 1.00 & 1.00 & 0.99 & 0.98 & 0.97 & 0.96 & 0.94 & 0.93 & 0.91 & 0.89 \\
1.33 & 1.33 & 1.32 & 1.30 & 1.29 & 1.26 & 1.24 & 1.21 & 1.17 & 1.14 & 1.11 \\
1.50 & 1.50 & 1.48 & 1.46 & 1.44 & 1.40 & 1.37 & 1.33 & 1.29 & 1.24 & 1.20 \\
1.67 & 1.66 & 1.65 & 1.62 & 1.58 & 1.54 & 1.49 & 1.44 & 1.39 & 1.34 & 1.28 \\
2.00 & 1.99 & 1.96 & 1.92 & 1.86 & 1.79 & 1.71 & 1.64 & 1.56 & 1.49 & 1.41 \\
2.50 & 2.48 & 2.43 & 2.34 & 2.24 & 2.12 & 2.00 & 1.88 & 1.77 & 1.66 & 1.56 \\
\hline
\end{tabular}

\section{Expected Value, Variance, and MSE}

Suppose that $\left\{\mathrm{X}_{i}, \mathrm{i}=1,2, \ldots, \mathrm{n}\right\}$ denote the random sample of size $\mathrm{n}$ from the quality characteristics $X$. To estimate the precision index $C_{p}$, we consider the natural estimator $\hat{\mathrm{C}}_{\mathrm{p}}$ defined below, where $\mathrm{S}=\left[\sum_{\mathrm{i}=1}^{\mathrm{n}}\left(\mathrm{X}_{i}-\overline{\mathrm{X}}\right) /(\mathrm{n}-1)\right]^{1 / 2}$ is the conventional estimator of $\sigma$, which may be obtained from a stable process,

$$
\hat{\mathrm{C}}_{\mathrm{p}}=\frac{\mathrm{USL}-\mathrm{LSL}}{6 \mathrm{~S}} .
$$

On the assumption of normality, the statistic $\mathrm{K}=(\mathrm{n}-1) \mathrm{S}^{2} / \sigma^{2}$ is distributed as $\chi_{\mathrm{n}-1}^{2}$, a chi-square with $\mathrm{n}-1$ degrees of freedom. The PDF (probability density function) of $\hat{\mathrm{C}}_{\mathrm{p}}$ can be expressed as (Chou and Owen, 1989)

$$
f(x)=2 \frac{\left(\sqrt{(n-1) / 2} C_{p}\right)^{n-1}}{\Gamma[(n-1) / 2]}(x)^{-n} \exp \left[-(n-1) C_{p}^{2}\left(2 x^{2}\right)^{-1}\right] .
$$

By adding the well-known correction factor

$$
b_{n-1}=\sqrt{\frac{2}{n-1}} \Gamma\left(\frac{n-1}{2}\right) \Gamma\left(\frac{n-2}{2}\right)^{-1}
$$

to $\hat{\mathrm{C}}_{\mathrm{p}}$, such as $\tilde{\mathrm{C}}_{\mathrm{p}}=\mathrm{b}_{\mathrm{n}-1} \hat{\mathrm{C}}_{\mathrm{P}}$, Pearn et al. (1992) showed that $\tilde{\mathrm{C}}_{\mathrm{P}}$ is the UMVUE (uniformly minimum variance unbiased estimator) of $\mathrm{C}_{\mathrm{p}}$. The expected value and the variance of the estimator $\tilde{\mathrm{C}}_{\mathrm{P}}$ are

$$
\mathrm{E}\left(\tilde{\mathrm{C}}_{\mathrm{p}}\right)=\mathrm{C}_{\mathrm{p}}, \quad \operatorname{Var}\left(\tilde{\mathrm{C}}_{\mathrm{p}}\right)=\left(\frac{\mathrm{n}-1}{\mathrm{n}-3} \mathrm{~b}_{\mathrm{n}-1}^{2}-1\right) \mathrm{C}_{\mathrm{p}}^{2}
$$


However, the sample observations are not $\left\{X_{i}, i=1,2, \ldots, n\right\}$ but $\left\{Y_{i}, i=\right.$ $1,2, \ldots, \mathrm{n}\}$. The estimator of estimating $\mathrm{C}_{\mathrm{p}}$ is

$$
\tilde{\mathrm{C}}_{\mathrm{p}}^{\mathrm{Y}}=\mathrm{b}_{\mathrm{n}-1}\left(\frac{\mathrm{USL}-\mathrm{LSL}}{6 \mathrm{~S}_{\mathrm{Y}}}\right)
$$

as we use $\tilde{C}_{P}$ to estimate $C_{p}$, where $S_{Y}=\left[\sum_{i=1}^{n}\left(Y_{i}-\bar{Y}\right) /(n-1)\right]^{1 / 2}$. Based on the same arguments used in Chou and Owen (1989) and Pearn et al. (1992), we obtain the PDF of $\tilde{C}_{\mathrm{P}}^{Y}$ as

$$
\mathrm{f}(\mathrm{y})=2 \frac{\left(\sqrt{(\mathrm{n}-1) / 2} \mathrm{C}_{\mathrm{p}} / \sqrt{1+\lambda^{2} \mathrm{C}_{\mathrm{p}}^{2}}\right)^{\mathrm{n}-1}}{\Gamma[(\mathrm{n}-1) / 2]}(\mathrm{y})^{-\mathrm{n}} \exp \left[\frac{-(\mathrm{n}-1) \mathrm{C}_{\mathrm{p}}^{2}\left(2 \mathrm{y}^{2}\right)^{-1}}{1+\lambda^{2} \mathrm{C}_{\mathrm{p}}^{2}}\right] .
$$

The expected value and the variance of the estimator $\tilde{\mathrm{C}}_{\mathrm{P}}^{\mathrm{Y}}$ are

$$
\mathrm{E}\left(\tilde{\mathrm{C}}_{\mathrm{p}}^{\mathrm{Y}}\right)=\frac{\mathrm{C}_{\mathrm{p}}}{\sqrt{1+\lambda^{2} \mathrm{C}_{\mathrm{p}}^{2}}}, \quad \operatorname{Var}\left(\tilde{\mathrm{C}}_{\mathrm{p}}^{\mathrm{Y}}\right)=\left(\frac{\mathrm{n}-1}{\mathrm{n}-3} \mathrm{~b}_{\mathrm{n}-1}^{2}-1\right) \frac{\mathrm{C}_{\mathrm{p}}^{2}}{1+\lambda^{2} \mathrm{C}_{\mathrm{p}}^{2}}
$$

For $\lambda>0$, it is obviously that $\tilde{C}_{\mathrm{P}}^{\mathrm{Y}}$ is a biased estimator of $\mathrm{C}_{\mathrm{p}}$, and the bias is $\left(1 / \sqrt{1+\lambda^{2} C_{P}^{2}}-1\right) C_{P}$, which decreases in $\lambda$. Since $n$ is a finite positive integer, $[(\mathrm{n}-1) /(\mathrm{n}-3)]\left(\mathrm{b}_{\mathrm{n}-1}\right)^{2}-1$ is positive, so we have $\operatorname{Var}\left(\tilde{\mathrm{C}}_{\mathrm{p}}^{\mathrm{Y}}\right)<\operatorname{Var}\left(\tilde{\mathrm{C}}_{\mathrm{p}}\right)$. Taking into account both the bias and the variance, we consider the MSEs of the two estimators $\tilde{\mathrm{C}}_{\mathrm{p}}$ and $\tilde{\mathrm{C}}_{\mathrm{p}}^{\mathrm{Y}}$. By the definition of $\mathrm{MSE}\left(\mathrm{MSE}=(\text { bias })^{2}+\right.$ variance $)$, the MSEs of $\tilde{\mathrm{C}}_{\mathrm{p}}$ and $\tilde{\mathrm{C}}_{\mathrm{p}}^{\mathrm{Y}}$, which we denote as $\operatorname{MSE}\left(\tilde{\mathrm{C}}_{\mathrm{p}}\right)$ and $\operatorname{MSE}\left(\tilde{\mathrm{C}}_{\mathrm{p}}^{\mathrm{Y}}\right)$, respectively, are

$$
\begin{aligned}
& \operatorname{MSE}\left(\tilde{\mathrm{C}}_{\mathrm{p}}\right)=\left(\frac{\mathrm{n}-1}{\mathrm{n}-3} \mathrm{~b}_{\mathrm{n}-1}^{2}-1\right) \mathrm{C}_{\mathrm{p}}^{2}, \\
& \operatorname{MSE}\left(\tilde{\mathrm{C}}_{\mathrm{p}}^{\mathrm{Y}}\right)=\left[\frac{\mathrm{n}-1}{\mathrm{n}-3}\left(\frac{\mathrm{b}_{\mathrm{n}-1}^{2}}{1+\lambda^{2} \mathrm{C}_{\mathrm{p}}^{2}}\right)-\frac{2}{\sqrt{1+\lambda^{2} \mathrm{C}_{\mathrm{p}}^{2}}}+1\right] \mathrm{C}_{\mathrm{p}}^{2} .
\end{aligned}
$$

To compare $\operatorname{MSE}\left(\tilde{\mathrm{C}}_{\mathrm{p}}^{\mathrm{Y}}\right)$ to $\operatorname{MSE}\left(\tilde{\mathrm{C}}_{\mathrm{p}}\right)$, we consider the function $\mathrm{f}\left(\mathrm{C}_{\mathrm{p}}, \mathrm{n}, \lambda\right)=$ $\operatorname{MSE}\left(\tilde{\mathrm{C}}_{\mathrm{P}}^{\mathrm{Y}}\right) / \operatorname{MSE}\left(\tilde{\mathrm{C}}_{\mathrm{P}}\right)$. By some reduction, we have $\mathrm{f}\left(\mathrm{C}_{\mathrm{P}}, \mathrm{n}, \lambda\right)=1$ if and only if 
(a)
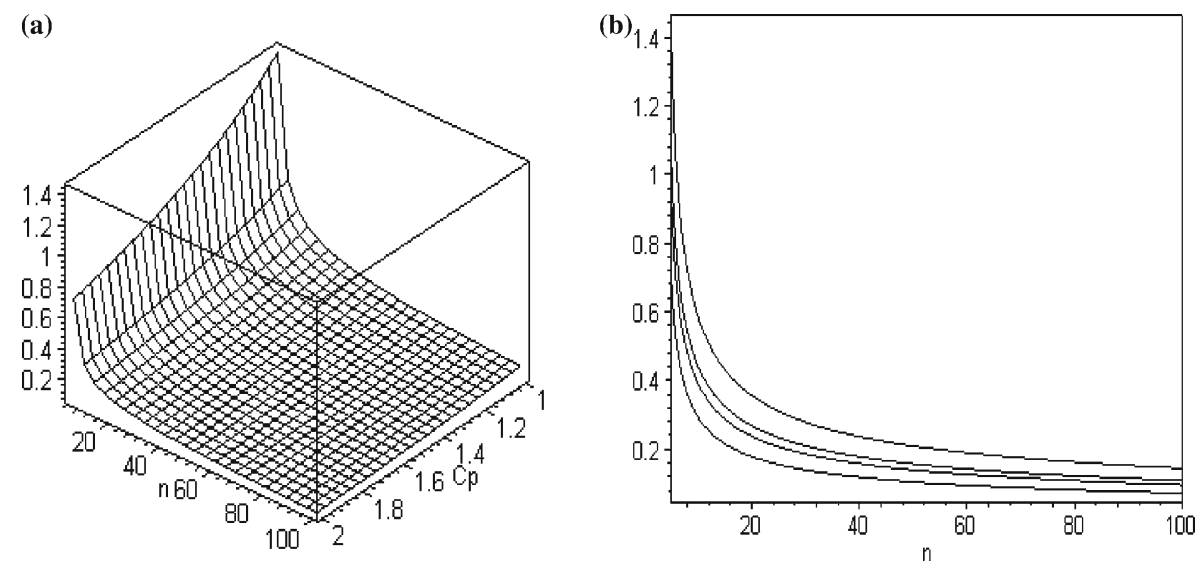

Figure 1. (a) Surface plot of $\lambda_{0}$ for various $\mathrm{n}=5$ (1) 100 and $\mathrm{C}_{\mathrm{p}}=[1.00,2.00]$ (b) plots of $\lambda_{0}$ versus $\mathrm{n}=5$ (1) 100 for $\mathrm{C}_{\mathrm{p}}=1.00,1.33,1.50,2.00$ (from top to bottom).

$$
\lambda=\frac{2 \sqrt{(\mathrm{n}-1) \mathrm{b}_{\mathrm{n}-1}^{2} /(\mathrm{n}-3)-1}}{2-(\mathrm{n}-1) \mathrm{b}_{\mathrm{n}-1}^{2} /(\mathrm{n}-3)} \mathrm{C}_{\mathrm{p}}^{-1}
$$

or $\lambda=0$. As we denote the right side of the equal sign in the above formula as $\lambda_{0}$, we have $\mathrm{f}\left(\mathrm{C}_{\mathrm{P}}, \mathrm{n}, \lambda\right)>1$ if $\lambda>\quad \lambda_{0}$ and $\mathrm{f}\left(\mathrm{C}_{\mathrm{P}}, \mathrm{n}, \lambda\right)<1$ if $\lambda<\lambda_{0}$ exclusive of 0 . It represents that $\operatorname{MSE}\left(\tilde{\mathrm{C}}_{\mathrm{P}}^{\mathrm{Y}}\right)>\operatorname{MSE}\left(\tilde{\mathrm{C}}_{\mathrm{P}}\right)$ if $\lambda>\lambda_{0}, \operatorname{MSE}\left(\tilde{\mathrm{C}}_{\mathrm{P}}^{\mathrm{Y}}\right)<$ $\operatorname{MSE}\left(\tilde{\mathrm{C}}_{\mathrm{P}}\right)$ if $\lambda<\lambda_{0}$ exclusive of 0 , and $\operatorname{MSE}\left(\tilde{\mathrm{C}}_{\mathrm{P}}^{\mathrm{Y}}\right)=\operatorname{MSE}\left(\tilde{\mathrm{C}}_{\mathrm{P}}\right)$ if $\lambda=\lambda_{0}$ or 0 . Figure 1(a) shows the surface plot of $\lambda_{0}$ values for $n=5(1) 100$ and $C_{p}$ in $[1.00,2.00]$. Figure 1 (b) plots $\lambda_{0}$ versus $n=5(1) 100$ for $C_{p}=1.00$, $1.33,1.50,2.00$. By those figures, we see that $\lambda_{0}$ value decreases if $\mathrm{n}$ or $\mathrm{C}_{\mathrm{p}}$ increases. The maximum value of $\lambda_{0}$ is 1.439 , which occurs at $\left(\mathrm{n}, \mathrm{C}_{\mathrm{p}}\right)=$ $(5,1.00)$, and the minimum value of $\lambda_{0}$ is 0.072 , which occurs at $\left(n, C_{p}\right)=$ $(100,2.00)$.

Figure 2(a)-(d) display the surface plots of the ratios $\gamma=\mathrm{f}\left(\mathrm{C}_{\mathrm{P}}, \mathrm{n}, \lambda\right)$ with $\mathrm{n}=5(1) 100$ and $\lambda$ in $[0,0.5]$ for $\mathrm{C}_{\mathrm{p}}=1.00,1.33,1.50$, and 2.00. $\gamma$ varies with $\mathrm{n}$ or $\lambda$, the variation is more noticeable in higher capability case. For large $\mathrm{n}, \gamma$ is greater than 1 for almost every value of $\lambda$, and $\gamma$ increases in $\lambda$. The maximum values of $\gamma$ in Figure 4(a)-(d) are 2.957, 6.110, 8.380, and 17.100, which occur at $(\mathrm{n}, \lambda)=(100,0.50),(100,0.50),(100,0.50)$, and $(100,0.50)$ respectively, and the minimum values of $\gamma$ in Figure 4(a)-(d) are 0.841 (1/1.189), 0.796 (1/1.256), 0.786 (1/1.272), and 0.785 (1/1.274), which occur at $(\mathrm{n}, \lambda)=(5,0.50),(5,0.50),(5,0.50)$, and $(5,0.39)$, respectively. The difference between $\operatorname{MSE}\left(\tilde{\mathrm{C}}_{\mathrm{P}}^{\mathrm{Y}}\right)$ and $\operatorname{MSE}\left(\tilde{\mathrm{C}}_{\mathrm{P}}\right)$ with $\gamma>1$ is more significant than that with $\gamma<1$. 
(a)
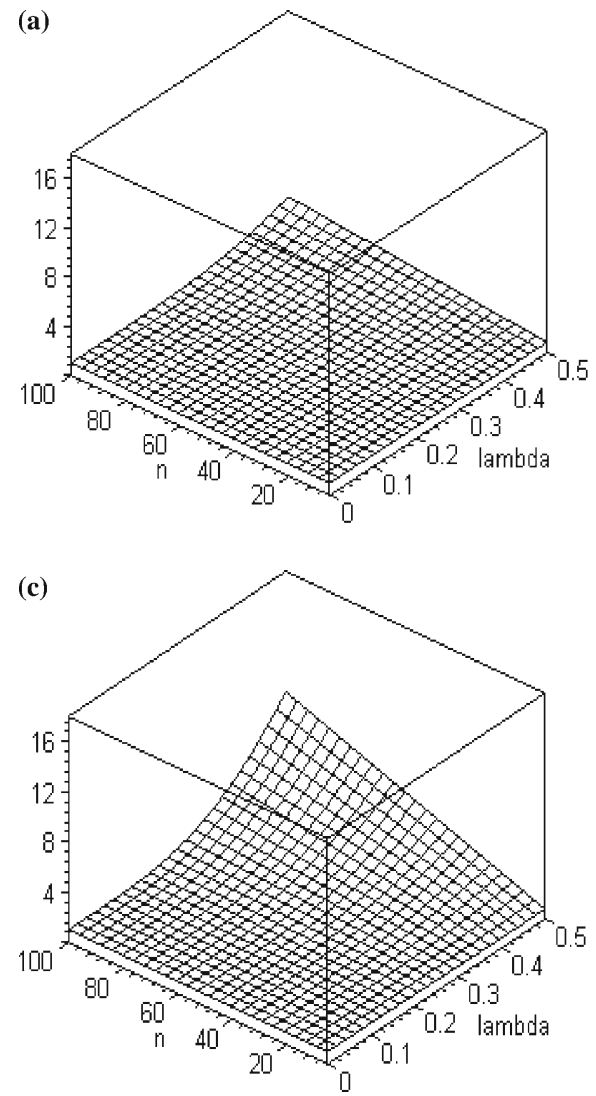
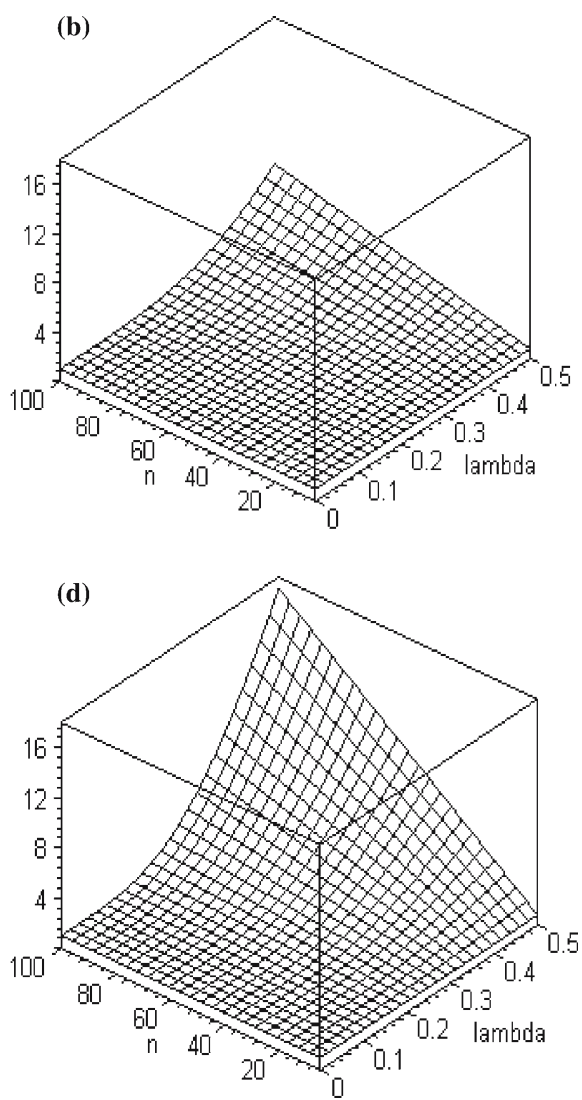

Figure 2. (a) Surface plot of $\gamma$ with $\mathrm{n}=5(1) 100$ and $\lambda$ in $[0,0.5]$ for $\mathrm{C}_{\mathrm{p}}=1.00$, (b) surface plot of $\gamma$ with $\mathrm{n}=5(1) 100$ and $\lambda$ in [0, 0.5] for $\mathrm{C}_{\mathrm{p}}=1.33$, (c) surface plot of $\gamma$ with $\mathrm{n}=5(1) 100$ and $\lambda$ in $[0,0.5]$ for $\mathrm{C}_{\mathrm{p}}=1.50$, (d) surface plot of $\gamma$ with $\mathrm{n}=$ $5(1) 100$ and $\lambda$ in $[0,0.5]$ for $C_{p}=2.00$.

\section{Confidence Interval Bounds}

Under normality assumption, the $(1-\alpha) \%$ confidence interval of $\mathrm{C}_{\mathrm{p}}$ with confidence bounds $\mathrm{L}$ and $\mathrm{U}$, can be established as

$$
\begin{aligned}
& \mathrm{P}\left(\mathrm{L} \leq \mathrm{C}_{\mathrm{p}} \leq \mathrm{U}\right)=\mathrm{P}\left(\mathrm{L} \leq \frac{\tilde{\mathrm{C}}_{\mathrm{p}}}{\mathrm{b}_{\mathrm{n}-1} \sqrt{\mathrm{n}-1}} \mathrm{~K}^{1 / 2} \leq \mathrm{U}\right) \\
& \quad=\mathrm{P}\left(\mathrm{L}^{2}\left[\frac{\mathrm{b}_{\mathrm{n}-1} \sqrt{\mathrm{n}-1}}{\tilde{\mathrm{C}}_{\mathrm{p}}}\right]^{2} \leq \mathrm{K} \leq \mathrm{U}^{2}\left[\frac{\mathrm{b}_{\mathrm{n}-1} \sqrt{\mathrm{n}-1}}{\tilde{\mathrm{C}}_{\mathrm{p}}}\right]^{2}\right)=1-\alpha, \\
& \mathrm{L}^{2}\left[\frac{\mathrm{b}_{\mathrm{n}-1} \sqrt{\mathrm{n}-1}}{\tilde{\mathrm{C}}_{\mathrm{p}}}\right]^{2}=\chi_{\mathrm{n}-1,1-\alpha / 2}^{2}, \quad \mathrm{U}^{2}\left[\frac{\mathrm{b}_{\mathrm{n}-1} \sqrt{\mathrm{n}-1}}{\tilde{\mathrm{C}}_{\mathrm{p}}}\right]^{2}=\chi_{\mathrm{n}-1, \alpha / 2}^{2},
\end{aligned}
$$


where $\chi_{\mathrm{n}-1, \alpha}^{2}$ is the upper $\alpha$ th quantile of the $\chi_{\mathrm{n}-1}^{2}$ distribution, and we can obtain the confidence bounds $\mathrm{L}$ and $\mathrm{U}$ of $\mathrm{C}_{\mathrm{p}}$ as

$$
\mathrm{L}=\frac{\sqrt{\chi_{\mathrm{n}-1,1-\alpha / 2}^{2}} \tilde{\mathrm{C}}_{\mathrm{p}}}{\sqrt{\mathrm{n}-1} \mathrm{~b}_{\mathrm{n}-1}}, \quad \mathrm{U}=\frac{\sqrt{\chi_{\mathrm{n}-1, \alpha / 2}^{2}} \tilde{\mathrm{C}}_{\mathrm{p}}}{\sqrt{\mathrm{n}-1} \mathrm{~b}_{\mathrm{n}-1}} .
$$

However, as a result of the measurement errors, we take $\tilde{\mathrm{C}}_{\mathrm{P}}^{\mathrm{Y}}$ as an estimator of $\mathrm{C}_{\mathrm{p}}$, thus the confidence bounds we calculated are

$$
\mathrm{L}^{\mathrm{Y}}=\frac{\sqrt{\chi_{\mathrm{n}-1,1-\alpha / 2}^{2}} \tilde{\mathrm{C}}_{\mathrm{p}}^{\mathrm{Y}}}{\sqrt{\mathrm{n}-1} b_{\mathrm{n}-1}}, \quad \mathrm{U}^{\mathrm{Y}}=\frac{\sqrt{\chi_{\mathrm{n}-1, \alpha / 2}^{2}} \tilde{\mathrm{C}}_{\mathrm{p}}^{\mathrm{Y}}}{\sqrt{\mathrm{n}-1} \mathrm{~b}_{\mathrm{n}-1}}
$$

and the confidence coefficient $\theta$ (the probability that the confidence interval contains the actual $C_{p}$ value) is

$$
\begin{aligned}
\theta & =P\left(\frac{\sqrt{\chi_{n-1,1-\alpha / 2}^{2}} \tilde{C}_{p}^{Y}}{\sqrt{n-1} b_{n-1}} \leq C_{p} \leq \frac{\sqrt{\chi_{n-1, \alpha / 2}^{2}} \tilde{C}_{p}^{Y}}{\sqrt{n-1} b_{n-1}}\right) \\
& =\mathrm{P}\left(\frac{\chi_{\mathrm{n}-1,1-\alpha / 2}^{2}(\mathrm{USL}-\mathrm{LSL})^{2}}{(\mathrm{n}-1) 36 \mathrm{~S}_{\mathrm{Y}}^{2}} \leq \mathrm{C}_{\mathrm{p}}^{2} \leq \frac{\chi_{\mathrm{n}-1, \alpha / 2}^{2}(\mathrm{USL}-\mathrm{LSL})^{2}}{(\mathrm{n}-1) 36 \mathrm{~S}_{\mathrm{Y}}^{2}}\right) \\
& =\mathrm{P}\left(\frac{1}{1+\lambda^{2} \mathrm{C}_{\mathrm{p}}^{2}} \chi_{\mathrm{n}-1,1-\alpha / 2}^{2} \leq \chi_{\mathrm{n}-1}^{2} \leq \frac{1}{1+\lambda^{2} \mathrm{C}_{\mathrm{p}}^{2}} \chi_{\mathrm{n}-1, \alpha / 2}^{2}\right)
\end{aligned}
$$

where $K^{Y}=(n-1) S_{Y}^{2} / \sigma_{Y}^{2}$ is distributed as $\chi_{n-1}^{2}$. Figure 3(a)-(d) present plots of $\theta$ versus $\lambda$ with $\mathrm{C}_{\mathrm{p}}=1.00,1.33,1.50,2.00$ and $\mathrm{n}=25(25) 100$ (from top to bottom) for $95 \%$ confidence intervals. Obviously, those intervals do not maintain the stated confidence coefficient. The $\theta$ value decreases in measurement errors, and larger sample size or higher capability has more significant decrements. Because of the measurement errors, the confidence coefficients may become very small. For instance, when $C_{p}=2.00, n=100$, and $\lambda=0.50$ (see Figure 3(d)), the confidence coefficient is only $0.26 \%$, which is much smaller than the stated confidence coefficient $95 \%$.

\section{Capability Testing Under Measurement Errors}

To determine whether a given process meets the present capability requirement and runs under the desired quality condition. We can consider the following statistical testing hypothesis, $\mathrm{H}_{0}: \mathrm{C}_{\mathrm{p}} \leq \mathrm{c}$ versus $\mathrm{H}_{1}: \mathrm{C}_{\mathrm{p}}>\mathrm{c}$. Process fails to meet the capability requirement if $\mathrm{C}_{\mathrm{p}} \leq \mathrm{c}$, and meets the capability requirement if $\mathrm{C}_{\mathrm{p}}>\mathrm{c}$. The critical value $\mathrm{c}_{0}$ can be determined by the 

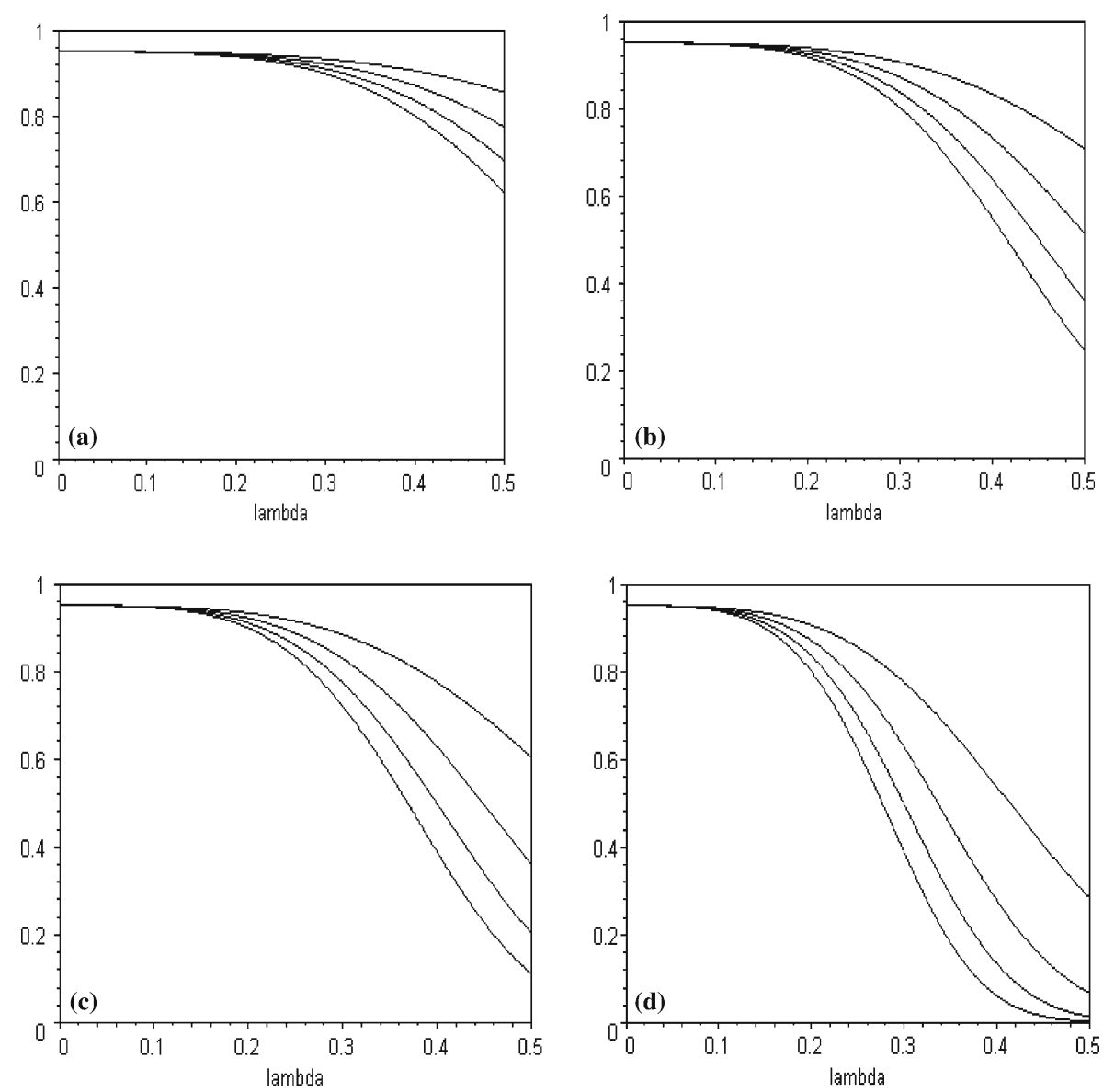

Figure 3. (a) Plots of $\theta$ versus $\lambda$ with $\mathrm{C}_{\mathrm{p}}=1.00$ and $\mathrm{n}=25(25) 100$ (from top to bottom) for $95 \%$ confidence intervals, (b) plots of $\theta$ versus $\lambda$ with $\mathrm{C}_{p}=1.33$ and $\mathrm{n}=$ 25(25)100 (from top to bottom) for 95\% confidence intervals, (c) plots of $\theta$ versus $\lambda$ with $\mathrm{C}_{p}=1.50$ and $\mathrm{n}=25(25) 100$ (from top to bottom) for $95 \%$ confidence intervals, (d) plots of $\theta$ versus $\lambda$ with $\mathrm{C}_{p}=2.00$ and $\mathrm{n}=25$ (25)100 (from top to bottom) for $95 \%$ confidence intervals.

following with $\alpha$-risk $\alpha\left(\mathrm{c}_{0}\right)=\alpha$ (the chance of incorrectly judging an incapable process as capable),

$$
\mathrm{P}\left(\tilde{\mathrm{C}}_{\mathrm{p}} \geq \mathrm{c}_{0} \mid \mathrm{C}_{\mathrm{p}}=\mathrm{c}\right)=\alpha
$$

and we can obtain $\mathrm{c}_{0}$ is

$$
\mathrm{c}_{0}=\frac{\mathrm{b}_{\mathrm{n}-1} \sqrt{\mathrm{n}-1} \mathrm{c}}{\sqrt{\chi_{\mathrm{n}-1,1-\alpha}^{2}}} .
$$


Meanwhile, the power of the test (the chance of correctly judging a capable process as capable) can be computed as

$$
\begin{aligned}
\pi\left(C_{p}\right) & =P\left(\tilde{C}_{p}>c_{0} \mid C_{p}\right)=P\left(b_{n-1}^{2} \frac{(U S L-L S L)^{2}}{36 S^{2}}>c_{0}^{2} \mid C_{p}\right) \\
& =\mathrm{P}\left(\mathrm{K}<\frac{\mathrm{b}_{\mathrm{n}-1}^{2}(\mathrm{n}-1) \mathrm{C}_{\mathrm{p}}^{2}}{\mathrm{c}_{0}^{2}}\right)=\mathrm{P}\left(\chi_{\mathrm{n}-1}^{2}<\frac{\mathrm{C}_{\mathrm{p}}^{2}}{\mathrm{c}^{2}} \chi_{\mathrm{n}-1,1-\alpha}^{2}\right) .
\end{aligned}
$$

In the presence of measurement errors, however, the $\alpha$-risk (denoted by $\alpha^{\mathrm{Y}}$ ) and the power of the test (denoted by $\pi^{\mathrm{Y}}$ ) are

$$
\begin{aligned}
& \alpha^{Y}=P\left(\tilde{C}_{p}^{Y} \geq c_{0} \mid C_{p}=c\right)
\end{aligned}
$$

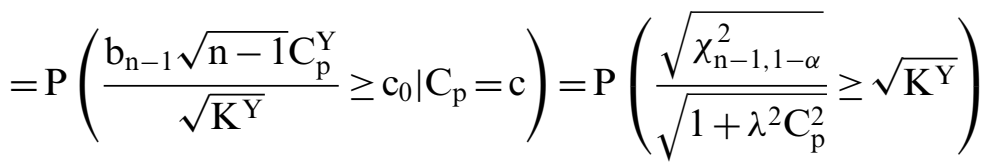

$$
\begin{aligned}
& =\mathrm{P}\left(\mathrm{K}^{\mathrm{Y}} \leq \frac{1}{1+\lambda^{2} \mathrm{C}_{\mathrm{p}}^{2}} \chi_{\mathrm{n}-1,1-\alpha}^{2}\right)=\mathrm{P}\left(\chi_{\mathrm{n}-1}^{2} \leq \frac{1}{1+\lambda^{2} \mathrm{C}_{\mathrm{p}}^{2}} \chi_{\mathrm{n}-1,1-\alpha}^{2}\right) \\
& \pi^{Y}\left(C_{p}\right)=P\left(\tilde{C}_{p}^{Y}>c_{0} \mid C_{p}\right) \\
& =P\left(\frac{b_{n-1} \sqrt{n-1} C_{p}^{Y}}{\sqrt{K^{Y}}}>c_{0} \mid C_{p}\right) \\
& =\mathrm{P}\left(\frac{\mathrm{C}_{\mathrm{p}}}{\sqrt{1+\lambda^{2} \mathrm{C}_{\mathrm{p}}^{2}}}>\frac{\mathrm{c}}{\sqrt{\chi_{\mathrm{n}-1,1-\alpha}^{2}}} \sqrt{\mathrm{K}^{\mathrm{Y}}}\right) \\
& =\mathrm{P}\left(\frac{\mathrm{C}_{\mathrm{p}}^{2} \chi_{\mathrm{n}-1,1-\alpha}^{2}}{\mathrm{c}^{2}\left(1+\lambda^{2} \mathrm{C}_{\mathrm{p}}^{2}\right)}>\mathrm{K}^{\mathrm{Y}}\right) \\
& =\mathrm{P}\left(\chi_{\mathrm{n}-1}^{2}<\frac{\mathrm{C}_{\mathrm{p}}^{2}}{\mathrm{c}^{2}\left(1+\lambda^{2} \mathrm{C}_{\mathrm{p}}^{2}\right)} \chi_{\mathrm{n}-1,1-\alpha}^{2}\right) \text {. }
\end{aligned}
$$

Since we underestimate the true capability of the process when we calculate process capability index using $\tilde{\mathrm{C}}_{\mathrm{P}}^{\mathrm{Y}}$ instead of $\tilde{\mathrm{C}}_{\mathrm{P}}$, the probability that $\tilde{\mathrm{C}}_{\mathrm{P}}^{\mathrm{Y}}$ is greater than $c_{0}$ will be less than the probability of that using $\tilde{\mathrm{C}}_{\mathrm{P}}$. Thus, the $\alpha$-risk using $\tilde{\mathrm{C}}_{\mathrm{P}}^{\mathrm{Y}}$ to estimate $\mathrm{C}_{\mathrm{p}}$ is less than the $\alpha$-risk using $\tilde{\mathrm{C}}_{\mathrm{P}}$ to estimate $\mathrm{C}_{\mathrm{p}}\left(\alpha^{\mathrm{Y}} \leq \alpha\right)$, and the power using $\tilde{\mathrm{C}}_{\mathrm{P}}^{\mathrm{Y}}$ to estimate $\mathrm{C}_{\mathrm{p}}$ is also less than the power using $\tilde{\mathrm{C}}_{\mathrm{P}}$ to estimate $\mathrm{C}_{\mathrm{p}}\left(\pi^{\mathrm{Y}} \leq \pi\right)$.

Figure 4(a)-(d) are the surface plots of $\alpha^{\mathrm{Y}}$ with $\mathrm{n}=5(1) 100$ and $\lambda$ in [0, 0.5 ] for $\mathrm{c}=1.00,1.33,1.50,2.00$, and $\alpha=0.05$. Figure $5(\mathrm{a})-(\mathrm{d})$ are plots of $\pi^{\mathrm{Y}}$ versus $\lambda$ with $\mathrm{n}=50$ and $\alpha=0.05$ for $\mathrm{c}=1.00,1.33,1.50,2.00$ and $\mathrm{C}_{\mathrm{p}}=\mathrm{c}(0.20) \mathrm{c}+1$. Note that we have $\alpha^{\mathrm{Y}}=\alpha$ and $\pi^{\mathrm{Y}}=\pi$ when $\lambda=0$ in those 

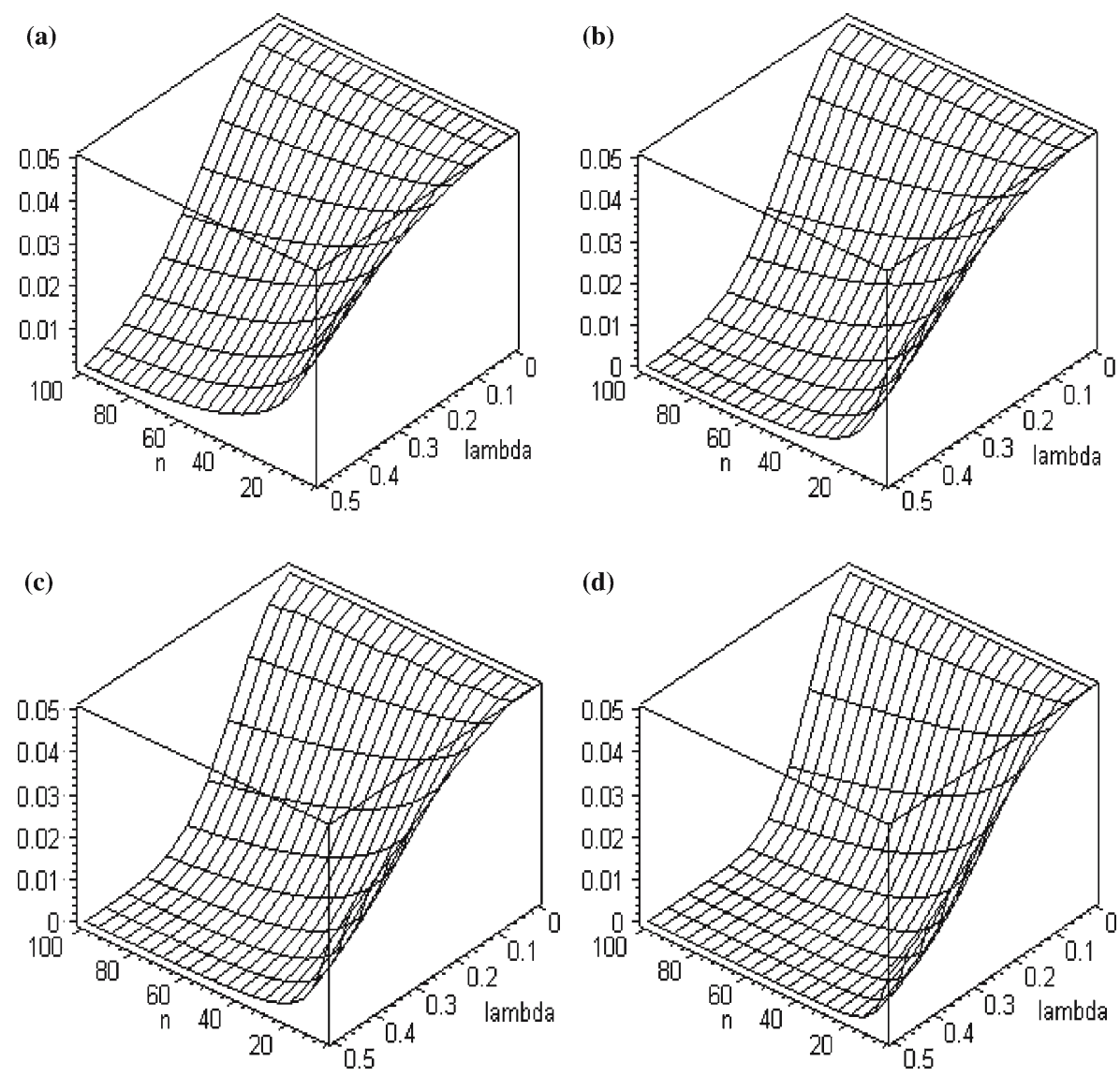

Figure 4. (a) Surface plot of $\alpha^{\mathrm{Y}}$ with $\mathrm{n}=5(1) 100$ and $\lambda$ in $[0,0.5]$ for $\mathrm{c}=1.00$ and $\alpha=0.05$, (b) surface plot of $\alpha^{\mathrm{Y}}$ with $\mathrm{n}=5(1) 100$ and $\lambda$ in $[0,0.5]$ for $\mathrm{c}=1.33$ and $\alpha=0.05$, (c) surface plot of $\alpha^{\mathrm{Y}}$ with $\mathrm{n}=5(1) 100$ and $\lambda$ in $[0,0.5]$ for $\mathrm{c}=1.50$ and $\alpha=0.05$, (d) surface plot of $\alpha^{\mathrm{Y}}$ with $\mathrm{n}=5(1) 100$ and $\lambda$ in $[0,0.5]$ for $\mathrm{c}=2.00$ and $\alpha=0.05$.

figures. In Figure 4(a)-(d), $\alpha^{\mathrm{Y}}$ decreases if $\lambda$ or $\mathrm{n}$ increases, and the decrements are significant with large $\mathrm{c}$ values. In addition, we find that large $\lambda$ values may result $\alpha^{\mathrm{Y}}$ smaller than $1 \times 10^{-4}$ (such as $\lambda=0.50, \mathrm{c}=2.00$, and $\mathrm{n} \geq 50$ ), an $\alpha$-risk may be very imperceptible because of measurement errors. In Figure 5(a)-(d), $\pi^{\mathrm{Y}}$ decreases with $\lambda$, but increases with $\mathrm{n}$. The decrements of power by $\lambda$ are more significant with higher capability. Because of measurement errors, $\pi^{\mathrm{Y}}$ may decrease with significant decrements. For instance, we consider the $\pi^{Y}$ values in Figure $5(\mathrm{~b})(\mathrm{c}=1.33, \mathrm{n}=50)$ for $\mathrm{C}_{\mathrm{p}}=1.93$, $\pi^{\mathrm{Y}}=0.980$ if there is no measurement error $(\lambda=0)$, but when $\lambda=0.50, \pi^{\mathrm{Y}}$ decreases to 0.104 , the decrement of power is about 0.88 . 
(a)

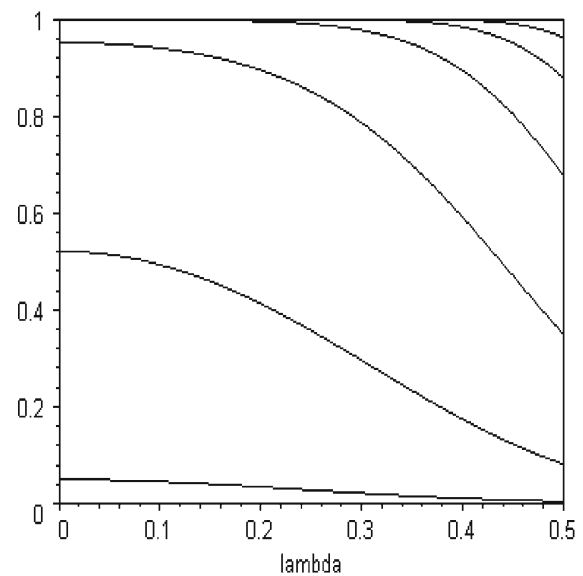

(c)

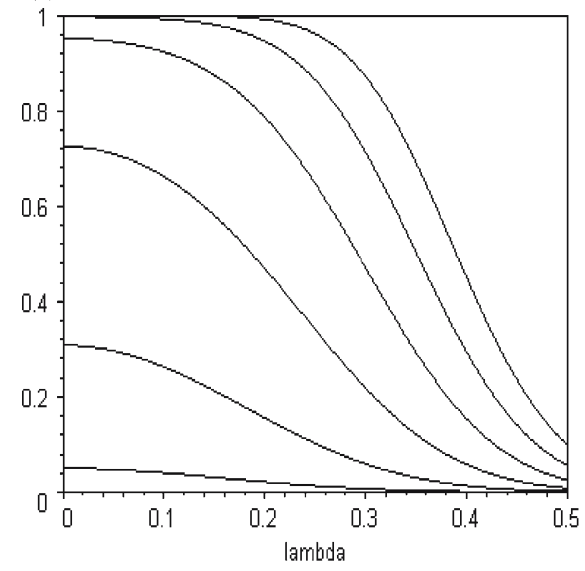

(b)

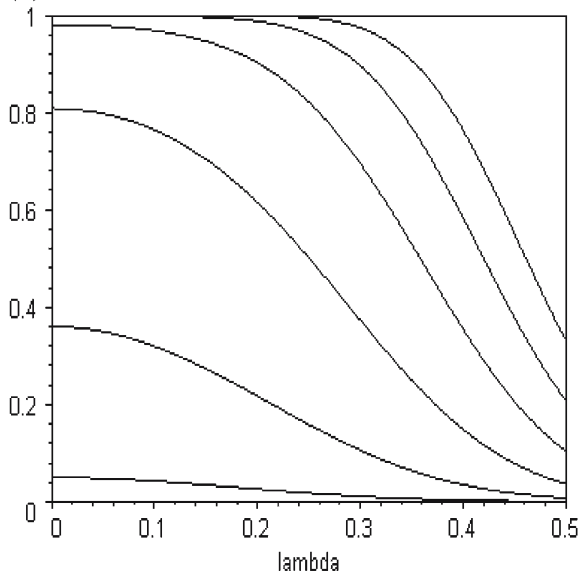

(d)

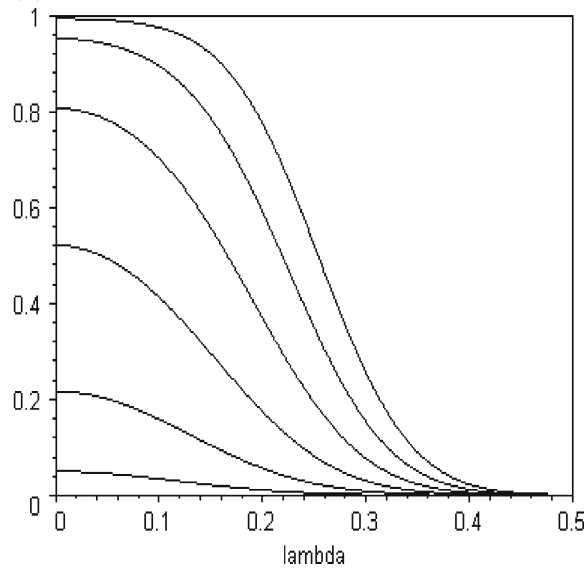

Figure 5. (a) Plots of $\pi^{\mathrm{Y}}$ versus $\lambda$ with $\mathrm{n}=50$ and $\alpha=0.05$ for $\mathrm{c}=1.00$ and $\mathrm{C}_{\mathrm{p}}=1.00(0.20) 2.00$ (from bottom to top), (b) plots of $\pi^{\mathrm{Y}}$ versus $\lambda$ with $\mathrm{n}=50$ and $\alpha=0.05$ for $\mathrm{c}=1.33$ and $\mathrm{C}_{\mathrm{p}}=1.33(0.20) 2.33$ (from bottom to top), (c) plots of $\pi^{\mathrm{Y}}$ versus $\lambda$ with $\mathrm{n}=50$ and $\alpha=0.05$ for $\mathrm{c}=1.50$ and $\mathrm{C}_{\mathrm{p}}=1.50(0.20) 2.50$ (from bottom to top), (d) plots of $\pi^{\mathrm{Y}}$ versus $\lambda$ with $\mathrm{n}=50$ and $\alpha=0.05$ for $\mathrm{c}=2.00$ and $\mathrm{C}_{\mathrm{p}}=2.00(0.20) 3.00$ (from bottom to top).

\section{Adjusted Confidence Bounds and Critical Values}

We showed earlier that the confidence intervals do not maintain the stated confidence coefficients. We also showed that both the $\alpha$-risk and the power of the test decrease when the gauge measurement error increases. If the producers do not take account of the effects of the gauge capability in process capability estimation and testing, it may result in serious loss. In that case, the producers cannot anymore affirm that their processes to be meet the capability requirement even if their processes are sufficiently capable. The producers may pay 
for a lot of cost because quantities of qualified product units are incorrectly rejected. Improving the gauge measurement accuracy and training the operators by proper education are essential for reducing the measurement errors. Nevertheless, measurement errors may be unavoidable in most manufacturing processes. In the following, we adjust the confidence intervals and critical values in order to ensure the intervals have the desired confidence coefficients and improve the power of the test with appropriate $\alpha$-risk. Suppose that the desired confidence coefficient is $1-\alpha$, the adjusted confidence interval of $\mathrm{C}_{\mathrm{p}}$ with confidence interval bounds $\mathrm{L}^{*}$ and $\mathrm{U}^{*}$, can be established as

$$
\begin{aligned}
& \mathrm{P}\left(\mathrm{L}^{*} \leq \mathrm{C}_{\mathrm{p}} \leq \mathrm{U}^{*}\right)=\mathrm{P}\left(\mathrm{L}^{*} \leq \frac{\tilde{\mathrm{C}}_{\mathrm{p}}^{\mathrm{Y}}}{\sqrt{(\mathrm{n}-1) \mathrm{b}_{\mathrm{n}-1}^{2}\left(\mathrm{~K}^{\mathrm{Y}}\right)^{-1}-\left(\lambda \tilde{\mathrm{C}}_{\mathrm{p}}^{\mathrm{Y}}\right)^{2}}} \leq \mathrm{U}^{*}\right) \\
& =P\left(L^{* 2}\left[\frac{(\mathrm{n}-1) b_{\mathrm{n}-1}^{2}\left(\mathrm{~K}^{\mathrm{Y}}\right)^{-1}-\left(\lambda \tilde{\mathrm{C}}_{\mathrm{p}}^{\mathrm{Y}}\right)^{2}}{\left(\tilde{\mathrm{C}}_{\mathrm{p}}^{\mathrm{Y}}\right)^{2}}\right]\right. \\
& \left.\leq 1 \leq \mathrm{U}^{* 2}\left[\frac{(\mathrm{n}-1) \mathrm{b}_{\mathrm{n}-1}^{2}\left(\mathrm{~K}^{\mathrm{Y}}\right)^{-1}-\left(\lambda \tilde{\mathrm{C}}_{\mathrm{p}}^{\mathrm{Y}}\right)^{2}}{\left(\tilde{\mathrm{C}}_{\mathrm{p}}^{\mathrm{Y}}\right)^{2}}\right]\right) \\
& =\mathrm{P}\left(\mathrm{L}^{* 2}\left[\frac{(\mathrm{n}-1) \mathrm{b}_{\mathrm{n}-1}^{2}\left(\mathrm{~K}^{\mathrm{Y}}\right)^{-1}}{\left(\tilde{\mathrm{C}}_{\mathrm{p}}^{\mathrm{Y}}\right)^{2}}\right] \leq 1+\mathrm{L}^{* 2} \lambda^{2}\right) \\
& +\mathrm{P}\left(1+\mathrm{U}^{* 2} \lambda^{2} \leq \mathrm{U}^{* 2}\left[\frac{(\mathrm{n}-1) \mathrm{b}_{\mathrm{n}-1}^{2}\left(\mathrm{~K}^{\mathrm{Y}}\right)^{-1}}{\left(\tilde{\mathrm{C}}_{\mathrm{p}}^{\mathrm{Y}}\right)^{2}}\right]\right) \\
& =\mathrm{P}\left(\mathrm{L}^{* 2}\left[\frac{(\mathrm{n}-1) \mathrm{b}_{\mathrm{n}-1}^{2}}{\left(\tilde{\mathrm{C}}_{\mathrm{p}}^{\mathrm{Y}}\right)^{2}\left(1+\mathrm{L}^{* 2} \lambda^{2}\right)}\right] \leq \mathrm{K}^{\mathrm{Y}} \leq \mathrm{U}^{* 2}\left[\frac{(\mathrm{n}-1) \mathrm{b}_{\mathrm{n}-1}^{2}}{\left(\tilde{\mathrm{C}}_{\mathrm{p}}^{\mathrm{Y}}\right)^{2}\left(1+\mathrm{U}^{* 2} \lambda^{2}\right)}\right]\right) \\
& =1-\alpha \\
& \mathrm{L}^{* 2}\left[\frac{(\mathrm{n}-1) \mathrm{b}_{\mathrm{n}-1}^{2}}{\left(\tilde{\mathrm{C}}_{\mathrm{p}}^{\mathrm{Y}}\right)^{2}\left(1+\mathrm{L}^{* 2} \lambda^{2}\right)}\right]=\chi_{\mathrm{n}-1,1-\alpha / 2}^{2}, \\
& \mathrm{U}^{* 2}\left[\frac{(\mathrm{n}-1) \mathrm{b}_{\mathrm{n}-1}^{2}}{\left(\tilde{\mathrm{C}}_{\mathrm{p}}^{\mathrm{Y}}\right)^{2}\left(1+\mathrm{U}^{* 2} \lambda^{2}\right)}\right]=\chi_{\mathrm{n}-1, \alpha / 2}^{2} \text {. }
\end{aligned}
$$

By some simplification, the adjusted $(1-\alpha) \%$ confidence interval bound can be written as

$$
\begin{aligned}
& \mathrm{L}^{*}=\frac{\sqrt{\chi_{\mathrm{n}-1,1-\alpha / 2}^{2}} \tilde{\mathrm{C}}_{\mathrm{p}}^{\mathrm{Y}}}{\sqrt{(\mathrm{n}-1) \mathrm{b}_{\mathrm{n}-1}^{2}-\left(\lambda \tilde{\mathrm{C}}_{\mathrm{p}}^{\mathrm{Y}}\right)^{2} \chi_{\mathrm{n}-1,1-\alpha / 2}^{2}}}, \\
& \mathrm{U}^{*}=\frac{\sqrt{\chi_{\mathrm{n}-1, \alpha / 2}^{2}} \tilde{\mathrm{C}}_{\mathrm{p}}^{\mathrm{Y}}}{\sqrt{(\mathrm{n}-1) \mathrm{b}_{\mathrm{n}-1}^{2}-\left(\lambda \tilde{\mathrm{C}}_{\mathrm{p}}^{\mathrm{Y}}\right)^{2} \chi_{\mathrm{n}-1, \alpha / 2}^{2}}}
\end{aligned}
$$


With our revised confidence interval bounds, we can ensure the interval would have the desired confidence coefficient. Moreover, in order to improve the power of the test, we let the critical values (denoted by $\mathrm{c}_{0}^{*}$ ) we proposed to be satisfied $\mathrm{c}_{0}^{*}<\mathrm{c}_{0}$. Since $\mathrm{c}_{0}^{*}<\mathrm{c}_{0}$, the probability that $\tilde{\mathrm{C}}_{\mathrm{P}}^{\mathrm{Y}}$ is greater than $\mathrm{c}_{0}^{*}$ will be more than the probability of that $\tilde{\mathrm{C}}_{\mathrm{P}}^{\mathrm{Y}}$ is greater than $\mathrm{c}_{0}$. And, both the $\alpha$-risk and the power increase when we take $\mathrm{c}_{0}^{*}$ to be critical value for testing hypothesis. Suppose that the $\alpha$-risk by our revised critical values $\mathrm{c}_{0}^{*}$ is $\alpha^{*}$, the revised critical $\mathrm{c}_{0}^{*}$ can be introduced by

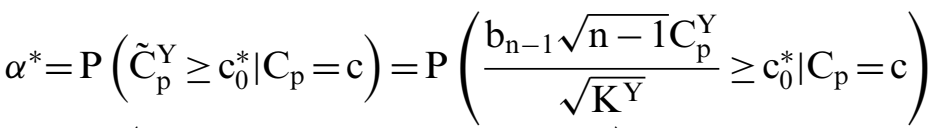

$$
\begin{aligned}
& =P\left(\frac{b_{n-1} \sqrt{n-1} C_{p}}{c_{0}^{*} \sqrt{1+\lambda^{2} C_{p}^{2}}} \geq \sqrt{\mathrm{K}^{\mathrm{Y}}} \mid C_{p}=c\right) \\
& =P\left(\frac{b_{n-1}^{2}(n-1) c^{2}}{c_{0}^{* 2}\left(1+\lambda^{2} c^{2}\right)} \geq K^{Y}\right) \\
& =P\left(\chi_{n-1}^{2} \leq \frac{b_{n-1}^{2}(n-1) c^{2}}{c_{0}^{* 2}\left(1+\lambda^{2} c^{2}\right)}\right) \text {. }
\end{aligned}
$$

To ensure that the $\alpha$-risk is within the preset magnitude, we let $\alpha^{*}=\alpha$, thus $\mathrm{c}_{0}^{*}$ and the power (denoted by $\pi^{*}$ ) can be obtained as

$$
\begin{aligned}
c_{0}^{*} & =\frac{b_{n-1} \sqrt{n-1} c}{\sqrt{\left(1+\lambda^{2} c^{2}\right) \chi_{n-1,1-\alpha}^{2}}} \\
\pi^{*}\left(C_{P}\right) & =P\left(\tilde{\mathrm{C}}_{\mathrm{P}}^{Y}>c_{0}^{*} \mid C_{p}\right)=P\left(\frac{b_{n-1} \sqrt{n-1} C_{p}^{Y}}{\sqrt{K^{Y}}}>c_{0}^{*} \mid C_{p}\right) \\
& =\mathrm{P}\left(\frac{\mathrm{C}_{\mathrm{p}} \sqrt{\left(1+\lambda^{2} \mathrm{c}^{2}\right) \chi_{\mathrm{n}-1,1-\alpha}^{2}}}{\mathrm{c} \sqrt{1+\lambda^{2} \mathrm{C}_{\mathrm{p}}^{2}}}>\sqrt{\mathrm{K}^{\mathrm{Y}}}\right) \\
& =\mathrm{P}\left(\chi_{\mathrm{n}-1}^{2}<\left(\frac{\mathrm{C}_{\mathrm{p}}}{\mathrm{c}}\right)^{2}\left(\frac{1+\lambda^{2} \mathrm{c}^{2}}{1+\lambda^{2} \mathrm{C}_{\mathrm{p}}^{2}}\right) \chi_{\mathrm{n}-1,1-\alpha}^{2}\right)
\end{aligned}
$$

Figure 6(a)-(d) are plots of $\pi^{*}$ versus $\lambda$ with $\mathrm{n}=50$ and $\alpha=0.05$ for $\mathrm{c}=$ $1.00,1.33,1.50,2.00$ and $\mathrm{C}_{\mathrm{p}}=\mathrm{c}(0.20) \mathrm{c}+1$. From those figures, we see that the powers corresponding to our adjusted critical values $\mathrm{c}_{0}^{*}$ remain decreasing in measurement error, but the decrements originated in our adjusted critical values $\mathrm{c}_{0}^{*}$ is smaller than those originated in the critical values with any corrections. For instance, when we compare the $\pi^{\mathrm{Y}}$ values in Figure 6(b) $(\mathrm{c}=1.33, \mathrm{n}=50)$ for $\mathrm{C}_{\mathrm{p}}=1.93$ to the $\pi^{*}$ values in Figure $7(\mathrm{~b})$ 
(a)

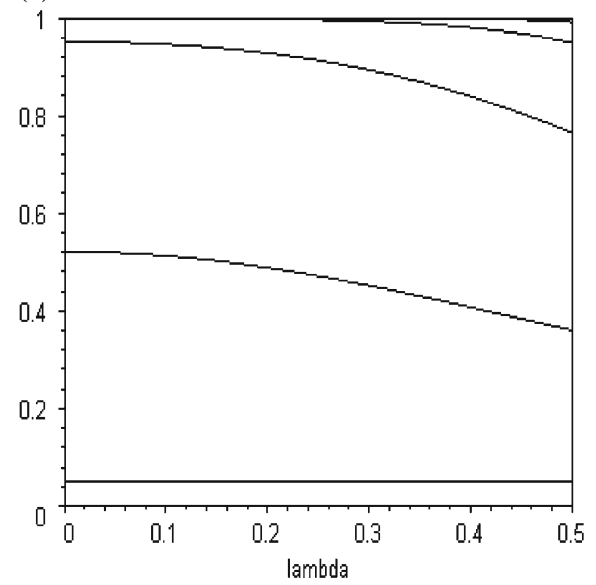

(c)

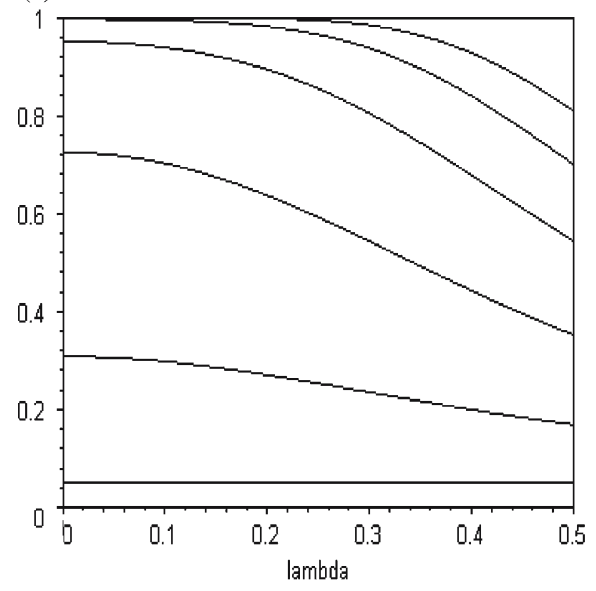

(b)

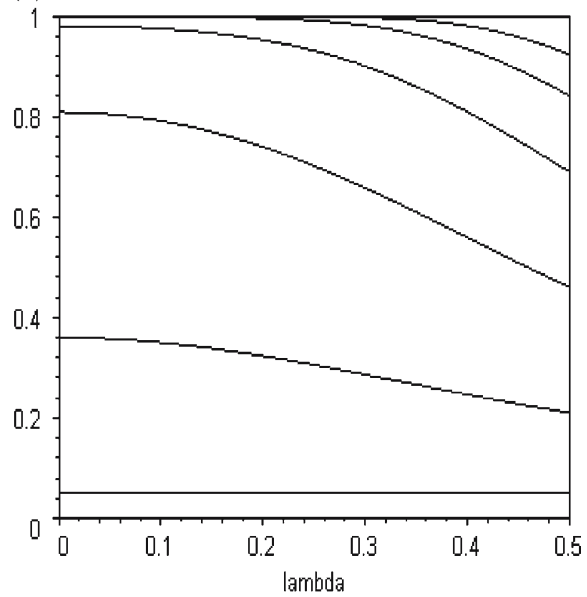

(d)

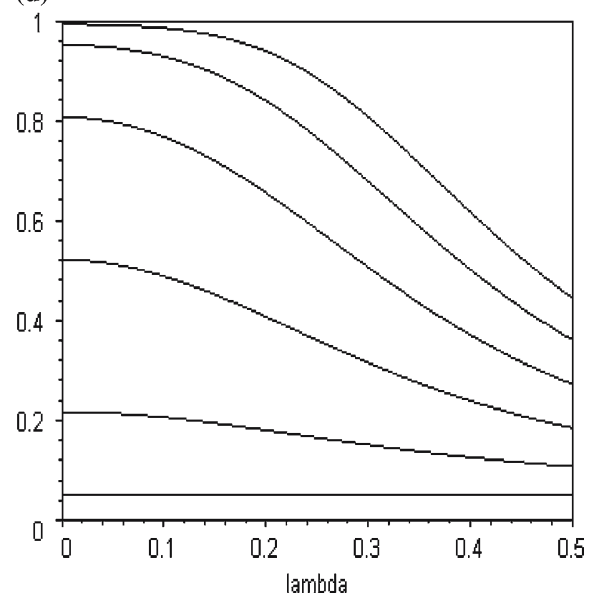

Figure 6. (a) Plots of $\pi^{*}$ versus $\lambda$ with $\mathrm{n}=50$ and $\alpha=0.05$ for $\mathrm{c}=1.00$ and $\mathrm{C}_{\mathrm{p}}=1.00(0.20) 2.00$ (from bottom to top), (b) plots of $\pi^{*}$ versus $\lambda$ with $\mathrm{n}=50$ and $\alpha=0.05$ for $\mathrm{c}=1.33$ and $\mathrm{C}_{\mathrm{p}}=1.33(0.20) 2.33$ (from bottom to top), (c) plots of $\pi^{*}$ versus $\lambda$ with $\mathrm{n}=50$ and $\alpha=0.05$ for $\mathrm{c}=1.50$ and $\mathrm{C}_{\mathrm{p}}=1.50(0.20) 2.50$ (from bottom to top), (d) plots of $\pi^{*}$ versus $\lambda$ with $\mathrm{n}=50$ and $\alpha=0.05$ for $\mathrm{c}=2.00$ and $\mathrm{C}_{\mathrm{p}}=2.00(0.20) 3.00$ (from bottom to top).

$(\mathrm{c}=1.33, \mathrm{n}=50)$ for $\mathrm{C}_{p}=1.93$, we obtain that $\pi^{\mathrm{Y}}=0.104$ and $\pi^{*}=0.690$ with $\lambda=0.50$. In this case, by our adjusted critical values $\mathrm{c}_{0}^{*}$, the power we improved is about 0.60 . With our revised critical values, we ensure the $\alpha$ risk within the preset magnitude and we have improved a certain degree of power. For our results to be practical, we provide the tables of our revised critical values for some commonly used capability requirements in Table V. Using those tables, the practitioner may skip the complex calculation and directly select the proper critical values for capability testing. 
Table V. Critical values for: (a) $\mathrm{C}_{\mathrm{p}}=1.00$, with $\mathrm{n}=10(10) 100, \lambda=0.05(0.05) 0.50$; (b) $\mathrm{C}_{\mathrm{p}}=1.33$, with $\mathrm{n}=10(10) 100, \lambda=0.05(0.05) 0.50 ; \quad$ (c) $\mathrm{C}_{\mathrm{p}}=1.50$, with $\mathrm{n}=10(10) 100$, $\lambda=0.05(0.05) 0.50 ;$ (d) $\mathrm{C}_{\mathrm{p}}=2.00$, with $\mathrm{n}=10(10) 100, \lambda=0.05(0.05) 0.50$

(a)

\begin{tabular}{|c|c|c|c|c|c|c|c|c|c|c|c|}
\hline \multirow[b]{2}{*}{$\mathrm{n}$} & \multirow[b]{2}{*}{$1-\alpha$} & \\
\hline & & 0.05 & 0.10 & 0.15 & 0.20 & 0.25 & 0.30 & 0.35 & 0.40 & 0.45 & 0.50 \\
\hline \multirow[t]{3}{*}{10} & 0.950 & 1.502 & 1.496 & 1.487 & 1.474 & 1.459 & 1.440 & 1.419 & 1.396 & 1.371 & 1.345 \\
\hline & 0.975 & 1.666 & 1.660 & 1.650 & 1.636 & 1.619 & 1.598 & 1.575 & 1.549 & 1.521 & 1.492 \\
\hline & 0.990 & 1.895 & 1.888 & 1.876 & 1.861 & 1.841 & 1.817 & 1.791 & 1.762 & 1.730 & 1.697 \\
\hline \multirow[t]{3}{*}{20} & 0.950 & 1.314 & 1.309 & 1.301 & 1.290 & 1.276 & 1.260 & 1.242 & 1.221 & 1.200 & 1.177 \\
\hline & 0.975 & 1.400 & 1.395 & 1.387 & 1.375 & 1.360 & 1.343 & 1.323 & 1.302 & 1.279 & 1.254 \\
\hline & 0.990 & 1.513 & 1.507 & 1.498 & 1.485 & 1.469 & 1.451 & 1.429 & 1.406 & 1.381 & 1.355 \\
\hline \multirow[t]{3}{*}{30} & 0.950 & 1.245 & 1.240 & 1.232 & 1.222 & 1.209 & 1.194 & 1.176 & 1.157 & 1.137 & 1.115 \\
\hline & 0.975 & 1.308 & 1.303 & 1.295 & 1.284 & 1.270 & 1.254 & 1.236 & 1.216 & 1.194 & 1.171 \\
\hline & 0.990 & 1.387 & 1.382 & 1.374 & 1.362 & 1.348 & 1.330 & 1.311 & 1.290 & 1.267 & 1.242 \\
\hline \multirow[t]{3}{*}{40} & 0.950 & 1.207 & 1.202 & 1.195 & 1.185 & 1.172 & 1.157 & 1.140 & 1.122 & 1.102 & 1.081 \\
\hline & 0.975 & 1.258 & 1.253 & 1.245 & 1.235 & 1.222 & 1.206 & 1.188 & 1.169 & 1.148 & 1.126 \\
\hline & 0.990 & 1.321 & 1.316 & 1.308 & 1.297 & 1.284 & 1.267 & 1.249 & 1.228 & 1.206 & 1.183 \\
\hline \multirow[t]{3}{*}{50} & 0.950 & 1.182 & 1.177 & 1.170 & 1.160 & 1.148 & 1.133 & 1.117 & 1.099 & 1.079 & 1.058 \\
\hline & 0.975 & 1.225 & 1.221 & 1.213 & 1.203 & & 1.175 & 1.158 & 1.139 & 1.119 & 1.097 \\
\hline & 0.990 & 1.280 & 1.275 & 1.267 & 1.256 & 1.243 & 1.227 & 1.209 & 1.190 & 1.168 & 1.146 \\
\hline \multirow[t]{3}{*}{60} & 0.950 & 1.164 & 1.160 & 1.152 & 1.143 & 1.131 & 1.116 & 1.100 & 1.082 & 1.063 & 1.042 \\
\hline & 0.975 & 1.203 & 1.198 & 1.191 & 1.181 & 1.168 & 1.153 & 1.136 & 1.118 & 1.098 & 1.077 \\
\hline & 0.990 & 1.250 & 1.246 & 1.238 & 1.227 & 1.214 & 1.199 & 1.181 & 1.162 & 1.142 & 1.120 \\
\hline \multirow[t]{3}{*}{70} & 0.950 & 1.150 & 1.146 & 1.139 & 1.129 & 1.117 & 1.103 & 1.087 & 1.069 & 1.050 & 1.030 \\
\hline & 0.975 & 1.185 & 1.181 & 1.174 & 1.164 & 1.151 & 1.137 & 1.120 & 1.102 & 1.082 & 1.062 \\
\hline & 0.990 & 1.228 & 1.224 & 1.216 & 1.206 & 1.193 & 1.178 & 1.161 & 1.142 & 1.121 & 1.100 \\
\hline \multirow[t]{3}{*}{80} & 0.950 & 1.140 & 1.135 & 1.128 & 1.119 & 1.107 & 1.093 & 1.077 & 1.059 & 1.041 & 1.021 \\
\hline & 0.975 & 1.172 & 1.167 & 1.160 & 1.150 & 1.138 & 1.124 & 1.107 & 1.089 & 1.070 & 1.049 \\
\hline & 0.990 & 1.211 & 1.206 & 1.199 & 1.189 & 1.176 & 1.161 & 1.144 & 1.126 & 1.106 & 1.084 \\
\hline \multirow[t]{3}{*}{90} & 0.950 & 1.131 & 1.127 & 1.120 & 1.110 & 1.098 & 1.085 & 1.069 & 1.051 & 1.033 & 1.013 \\
\hline & 0.975 & 1.161 & 1.156 & 1.149 & 1.140 & 1.127 & 1.113 & 1.097 & 1.079 & 1.060 & 1.039 \\
\hline & 0.990 & 1.197 & 1.192 & 1.185 & 1.175 & 1.163 & 1.148 & 1.131 & 1.113 & 1.093 & 1.072 \\
\hline \multirow[t]{3}{*}{100} & 0.950 & 1.124 & 1.119 & 1.112 & 1.103 & 1.091 & 1.077 & 1.062 & 1.044 & 1.026 & 1.006 \\
\hline & 0.975 & 1.151 & 1.147 & 1.140 & 1.130 & 1.118 & 1.104 & 1.088 & 1.070 & 1.051 & 1.031 \\
\hline & 0.990 & 1.185 & 1.181 & 1.174 & 1.164 & 1.151 & 1.137 & 1.120 & 1.102 & 1.082 & 1.061 \\
\hline
\end{tabular}


Table V. continued

(b)

\begin{tabular}{|c|c|c|c|c|c|c|c|c|c|c|c|}
\hline \multirow[b]{2}{*}{$\mathrm{n}$} & \multirow[b]{2}{*}{$1-\alpha$} & \multicolumn{10}{|c|}{$\lambda$} \\
\hline & & 0.05 & 0.10 & 0.15 & 0.20 & 0.25 & 0.30 & 0.35 & 0.40 & 0.45 & 0.50 \\
\hline \multirow[t]{3}{*}{10} & 0.950 & 1.995 & 1.982 & 1.961 & 1.932 & 1.898 & 1.857 & 1.813 & 1.765 & 1.716 & 1.665 \\
\hline & 0.975 & 2.214 & 2.200 & 2.176 & 2.144 & 2.106 & 2.061 & 2.012 & 1.959 & 1.904 & 1.848 \\
\hline & 0.990 & 2.518 & 2.501 & 2.475 & 2.439 & 2.395 & 2.344 & 2.288 & 2.228 & 2.165 & 2.101 \\
\hline \multirow[t]{3}{*}{20} & 0.950 & 1.746 & 1.734 & 1.716 & 1.691 & 1.660 & 1.625 & 1.586 & 1.545 & 1.501 & 1.457 \\
\hline & 0.975 & 1.861 & 1.848 & 1.829 & 1.802 & 1.769 & 1.732 & 1.690 & 1.646 & 1.600 & 1.553 \\
\hline & 0.990 & 2.010 & 1.997 & 1.975 & 1.947 & 1.911 & 1.871 & 1.826 & 1.778 & 1.728 & 1.677 \\
\hline \multirow[t]{3}{*}{30} & 0.950 & 1.654 & 1.643 & 1.626 & 1.602 & 1.573 & 1.540 & 1.503 & 1.463 & 1.422 & 1.380 \\
\hline & 0.975 & 1.737 & 1.726 & 1.708 & 1.683 & 1.652 & 1.617 & 1.579 & 1.537 & 1.494 & 1.450 \\
\hline & 0.990 & 1.843 & 1.831 & 1.812 & 1.785 & 1.753 & 1.716 & 1.675 & 1.631 & 1.585 & 1.538 \\
\hline \multirow[t]{3}{*}{40} & 0.950 & 1.603 & 1.593 & 1.576 & 1.553 & 1.525 & 1.492 & 1.457 & 1.419 & 1.379 & 1.338 \\
\hline & 0.975 & 1.671 & 1.660 & 1.642 & 1.618 & 1.589 & 1.555 & 1.518 & 1.478 & 1.437 & 1.394 \\
\hline & 0.990 & 1.756 & 1.744 & 1.726 & 1.700 & 1.670 & 1.634 & 1.595 & 1.553 & 1.510 & 1.465 \\
\hline \multirow[t]{3}{*}{50} & 0.950 & 1.570 & 1.560 & 1.543 & 1.521 & 1.493 & 1.462 & 1.427 & 1.389 & 1.350 & 1.310 \\
\hline & 0.975 & 1.628 & 1.618 & 1.600 & 1.577 & 1.548 & 1.516 & 1.479 & 1.441 & 1.400 & 1.359 \\
\hline & 0.990 & 1.700 & 1.689 & 1.671 & 1.647 & 1.617 & 1.583 & 1.545 & 1.504 & 1.462 & 1.419 \\
\hline \multirow[t]{3}{*}{60} & 0.950 & 1.547 & 1.536 & 1.520 & 1.498 & 1.471 & 1.440 & 1.405 & 1.368 & 1.330 & 1.291 \\
\hline & 0.975 & 1.598 & 1.587 & 1.570 & 1.548 & 1.520 & 1.487 & 1.452 & 1.414 & 1.374 & 1.333 \\
\hline & 0.990 & 1.661 & 1.650 & 1.633 & 1.609 & 1.580 & 1.546 & 1.509 & 1.470 & 1.429 & 1.386 \\
\hline \multirow[t]{3}{*}{70} & 0.950 & 1.529 & 1.519 & 1.502 & 1.480 & 1.454 & 1.423 & 1.389 & 1.352 & 1.314 & 1.276 \\
\hline & 0.975 & 1.575 & 1.565 & 1.548 & 1.525 & 1.498 & 1.466 & 1.431 & 1.394 & 1.354 & 1.314 \\
\hline & 0.990 & 1.632 & 1.621 & 1.604 & 1.581 & 1.552 & 1.519 & 1.483 & 1.444 & 1.403 & 1.362 \\
\hline \multirow[t]{3}{*}{80} & 0.950 & 1.514 & 1.504 & 1.488 & 1.467 & 1.440 & 1.410 & 1.376 & 1.340 & 1.302 & 1.264 \\
\hline & 0.975 & 1.557 & 1.547 & 1.530 & 1.508 & 1.481 & 1.449 & 1.415 & 1.378 & 1.339 & 1.299 \\
\hline & 0.990 & 1.609 & 1.598 & 1.581 & 1.558 & 1.530 & 1.498 & 1.462 & 1.424 & 1.384 & 1.343 \\
\hline \multirow[t]{3}{*}{90} & 0.950 & 1.503 & 1.493 & 1.477 & 1.455 & 1.429 & 1.399 & 1.365 & 1.330 & 1.292 & 1.254 \\
\hline & 0.975 & 1.542 & 1.532 & 1.516 & 1.494 & 1.467 & 1.436 & 1.401 & 1.365 & 1.326 & 1.287 \\
\hline & 0.990 & 1.590 & 1.580 & 1.563 & 1.540 & 1.512 & 1.480 & 1.445 & 1.407 & 1.368 & 1.327 \\
\hline \multirow[t]{3}{*}{100} & 0.950 & 1.493 & 1.483 & 1.467 & 1.446 & 1.420 & 1.390 & 1.356 & 1.321 & 1.284 & 1.246 \\
\hline & 0.975 & 1.530 & 1.520 & 1.504 & 1.482 & 1.455 & 1.424 & 1.390 & 1.354 & 1.316 & 1.277 \\
\hline & 0.990 & 1.575 & 1.565 & 1.548 & 1.525 & 1.498 & 1.466 & 1.431 & 1.393 & 1.354 & 1.314 \\
\hline
\end{tabular}


Table $V$. continued

(c)

\begin{tabular}{|c|c|c|c|c|c|c|c|c|c|c|c|}
\hline \multirow[b]{2}{*}{$\mathrm{n}$} & \multirow[b]{2}{*}{$1-\alpha$} & \multicolumn{10}{|c|}{$\lambda$} \\
\hline & & 0.05 & 0.10 & 0.15 & 0.20 & 0.25 & 0.30 & 0.35 & 0.40 & 0.45 & 0.50 \\
\hline \multirow[t]{3}{*}{10} & 0.950 & 2.249 & 2.230 & 2.200 & 2.160 & 2.112 & 2.057 & 1.997 & 1.934 & 1.869 & 1.804 \\
\hline & 0.975 & 2.496 & 2.475 & 2.442 & 2.397 & 2.343 & 2.282 & 2.216 & 2.146 & 2.074 & 2.002 \\
\hline & 0.990 & 2.838 & 2.815 & 2.777 & 2.726 & 2.665 & 2.595 & 2.520 & 2.440 & 2.359 & 2.277 \\
\hline \multirow[t]{3}{*}{20} & 0.950 & 1.968 & 1.951 & 1.925 & 1.890 & 1.848 & 1.799 & 1.747 & 1.692 & 1.635 & 1.579 \\
\hline & 0.975 & 2.097 & 2.080 & 2.052 & 2.014 & 1.969 & 1.918 & 1.862 & 1.803 & 1.743 & 1.682 \\
\hline & 0.990 & 2.265 & 2.247 & 2.216 & 2.176 & 2.127 & 2.072 & 2.011 & 1.948 & 1.883 & 1.817 \\
\hline \multirow[t]{3}{*}{30} & 0.950 & 1.864 & 1.849 & 1.824 & 1.791 & 1.750 & 1.705 & 1.655 & 1.603 & 1.549 & 1.496 \\
\hline & 0.975 & 1.958 & 1.942 & 1.916 & 1.881 & 1.839 & 1.791 & 1.739 & 1.684 & 1.628 & 1.571 \\
\hline & 0.990 & 2.078 & 2.060 & 2.033 & 1.996 & 1.951 & 1.900 & 1.845 & 1.787 & 1.727 & 1.667 \\
\hline \multirow[t]{3}{*}{40} & 0.950 & 1.807 & 1.792 & 1.768 & 1.736 & 1.697 & 1.653 & 1.604 & 1.554 & 1.502 & 1.450 \\
\hline & 0.975 & 1.883 & 1.868 & 1.843 & 1.809 & 1.768 & 1.722 & 1.672 & 1.620 & 1.565 & 1.511 \\
\hline & 0.990 & 1.979 & 1.963 & 1.936 & 1.901 & 1.858 & 1.810 & 1.757 & 1.702 & 1.645 & 1.588 \\
\hline \multirow[t]{3}{*}{50} & 0.950 & 1.770 & 1.755 & 1.732 & 1.700 & 1.662 & 1.619 & 1.571 & 1.522 & 1.471 & 1.420 \\
\hline & 0.975 & 1.835 & 1.820 & 1.796 & 1.763 & 1.723 & 1.678 & 1.630 & 1.578 & 1.525 & 1.472 \\
\hline & 0.990 & 1.916 & 1.900 & 1.875 & 1.841 & 1.799 & 1.752 & 1.702 & 1.648 & 1.593 & 1.537 \\
\hline \multirow[t]{3}{*}{60} & 0.950 & 1.743 & 1.729 & 1.705 & 1.674 & 1.637 & 1.594 & 1.548 & 1.499 & 1.449 & 1.398 \\
\hline & 0.975 & 1.801 & 1.786 & 1.762 & 1.730 & 1.691 & 1.647 & 1.599 & 1.549 & 1.497 & 1.445 \\
\hline & 0.990 & 1.872 & 1.857 & 1.832 & 1.798 & 1.758 & 1.712 & 1.662 & 1.610 & 1.556 & 1.502 \\
\hline \multirow[t]{3}{*}{70} & 0.950 & 1.723 & 1.709 & 1.686 & 1.655 & 1.618 & 1.576 & 1.530 & 1.482 & 1.432 & 1.382 \\
\hline & 0.975 & 1.775 & 1.761 & 1.737 & 1.705 & 1.667 & 1.623 & 1.576 & 1.527 & 1.476 & 1.424 \\
\hline & 0.990 & 1.839 & 1.824 & 1.800 & 1.767 & 1.727 & 1.682 & 1.633 & 1.582 & 1.529 & 1.476 \\
\hline \multirow[t]{3}{*}{80} & 0.950 & 1.707 & 1.693 & 1.670 & 1.639 & 1.603 & 1.561 & 1.515 & 1.468 & 1.419 & 1.369 \\
\hline & 0.975 & 1.755 & 1.740 & 1.717 & 1.686 & 1.648 & 1.605 & 1.558 & 1.509 & 1.459 & 1.408 \\
\hline & 0.990 & 1.814 & 1.798 & 1.774 & 1.742 & 1.703 & 1.658 & 1.610 & 1.559 & 1.507 & 1.455 \\
\hline \multirow[t]{3}{*}{90} & 0.950 & 1.694 & 1.680 & 1.657 & 1.627 & 1.590 & 1.549 & 1.504 & 1.456 & 1.408 & 1.359 \\
\hline & 0.975 & 1.738 & 1.724 & 1.701 & 1.670 & 1.632 & 1.590 & 1.543 & 1.495 & 1.445 & 1.395 \\
\hline & 0.990 & 1.793 & 1.778 & 1.754 & 1.722 & 1.683 & 1.639 & 1.592 & 1.541 & 1.490 & 1.438 \\
\hline \multirow[t]{3}{*}{100} & 0.950 & 1.683 & 1.669 & 1.646 & 1.616 & 1.580 & 1.539 & 1.494 & 1.447 & 1.399 & 1.350 \\
\hline & 0.975 & 1.724 & 1.710 & 1.687 & 1.656 & 1.619 & 1.577 & 1.531 & 1.483 & 1.433 & 1.383 \\
\hline & 0.990 & 1.775 & 1.760 & 1.737 & 1.705 & 1.667 & 1.623 & 1.576 & 1.526 & 1.475 & 1.424 \\
\hline
\end{tabular}


Table $V$. continued

(d)

\begin{tabular}{|c|c|c|c|c|c|c|c|c|c|c|c|}
\hline \multirow[b]{2}{*}{$\mathrm{n}$} & \multirow[b]{2}{*}{$1-\alpha$} & \multicolumn{10}{|c|}{$\lambda$} \\
\hline & & 0.05 & 0.10 & 0.15 & 0.20 & 0.25 & 0.30 & 0.35 & 0.40 & 0.45 & 0.50 \\
\hline \multirow[t]{3}{*}{10} & 0.950 & 2.992 & 2.949 & 2.880 & 2.792 & 2.690 & 2.578 & 2.463 & 2.348 & 2.235 & 2.126 \\
\hline & 0.975 & 3.320 & 3.272 & 3.196 & 3.098 & 2.984 & 2.861 & 2.734 & 2.606 & 2.480 & 2.359 \\
\hline & 0.990 & 3.776 & 3.721 & 3.635 & 3.523 & 3.394 & 3.254 & 3.109 & 2.963 & 2.821 & 2.683 \\
\hline \multirow[t]{3}{*}{20} & 0.950 & 2.618 & 2.580 & 2.520 & 2.443 & 2.353 & 2.256 & 2.155 & 2.054 & 1.956 & 1.860 \\
\hline & 0.975 & 2.790 & 2.750 & 2.686 & 2.603 & 2.508 & 2.404 & 2.297 & 2.190 & 2.084 & 1.983 \\
\hline & 0.990 & 3.014 & 2.970 & 2.901 & 2.812 & 2.709 & 2.597 & 2.481 & 2.365 & 2.251 & 2.142 \\
\hline \multirow[t]{3}{*}{30} & 0.950 & 2.480 & 2.444 & 2.387 & 2.314 & 2.229 & 2.137 & 2.042 & 1.946 & 1.853 & 1.762 \\
\hline & 0.975 & 2.605 & 2.568 & 2.508 & 2.431 & 2.342 & 2.245 & 2.145 & 2.045 & 1.946 & 1.851 \\
\hline & 0.990 & 2.764 & 2.724 & 2.661 & 2.579 & 2.485 & 2.382 & 2.276 & 2.169 & 2.065 & 1.964 \\
\hline \multirow[t]{3}{*}{40} & 0.950 & 2.404 & 2.369 & 2.314 & 2.243 & 2.161 & 2.072 & 1.979 & 1.887 & 1.796 & 1.709 \\
\hline & 0.975 & 2.506 & 2.469 & 2.412 & 2.338 & 2.252 & 2.159 & 2.063 & 1.966 & 1.872 & 1.781 \\
\hline & 0.990 & 2.633 & 2.595 & 2.534 & 2.457 & 2.367 & 2.269 & 2.168 & 2.066 & 1.967 & 1.871 \\
\hline \multirow[t]{3}{*}{50} & 0.950 & 2.355 & 2.320 & 2.267 & 2.197 & 2.117 & 2.029 & 1.939 & 1.848 & 1.759 & 1.673 \\
\hline & 0.975 & 2.442 & 2.406 & 2.350 & 2.278 & 2.195 & 2.104 & 2.010 & 1.916 & 1.824 & 1.735 \\
\hline & 0.990 & 2.550 & 2.513 & 2.454 & 2.379 & 2.292 & 2.197 & 2.099 & 2.001 & 1.905 & 1.812 \\
\hline \multirow[t]{3}{*}{60} & 0.950 & 2.319 & 2.286 & 2.232 & 2.164 & 2.085 & 1.999 & 1.909 & 1.820 & 1.732 & 1.648 \\
\hline & 0.975 & 2.396 & 2.361 & 2.307 & 2.236 & 2.154 & 2.065 & 1.973 & 1.880 & 1.790 & 1.703 \\
\hline & 0.990 & 2.491 & 2.455 & 2.398 & 2.324 & 2.239 & 2.147 & 2.051 & 1.955 & 1.861 & 1.770 \\
\hline \multirow[t]{3}{*}{70} & 0.950 & 2.292 & 2.259 & 2.207 & 2.139 & 2.060 & 1.975 & 1.887 & 1.799 & 1.712 & 1.629 \\
\hline & 0.975 & 2.362 & 2.328 & 2.274 & 2.204 & 2.123 & 2.035 & 1.945 & 1.853 & 1.764 & 1.678 \\
\hline & 0.990 & 2.447 & 2.412 & 2.356 & 2.283 & 2.200 & 2.109 & 2.015 & 1.920 & 1.828 & 1.739 \\
\hline \multirow[t]{3}{*}{80} & 0.950 & 2.271 & 2.238 & 2.186 & 2.119 & 2.041 & 1.957 & 1.870 & 1.782 & 1.696 & 1.614 \\
\hline & 0.975 & 2.335 & 2.301 & 2.247 & 2.179 & 2.099 & 2.012 & 1.922 & 1.832 & 1.744 & 1.659 \\
\hline & 0.990 & 2.413 & 2.378 & 2.323 & 2.251 & 2.169 & 2.079 & 1.986 & 1.893 & 1.802 & 1.715 \\
\hline \multirow[t]{3}{*}{90} & 0.950 & 2.253 & 2.221 & 2.169 & 2.103 & 2.026 & 1.942 & 1.855 & 1.768 & 1.683 & 1.601 \\
\hline & 0.975 & 2.313 & 2.279 & 2.226 & 2.158 & 2.079 & 1.993 & 1.904 & 1.815 & 1.728 & 1.643 \\
\hline & 0.990 & 2.385 & 2.350 & 2.296 & 2.225 & 2.144 & 2.055 & 1.964 & 1.872 & 1.782 & 1.695 \\
\hline \multirow[t]{3}{*}{100} & 0.950 & 2.239 & 2.206 & 2.155 & 2.089 & 2.012 & 1.929 & 1.843 & 1.757 & 1.672 & 1.591 \\
\hline & 0.975 & 2.294 & 2.261 & 2.208 & 2.141 & 2.062 & 1.977 & 1.889 & 1.800 & 1.714 & 1.630 \\
\hline & 0.990 & 2.362 & 2.327 & 2.273 & 2.204 & 2.123 & 2.035 & 1.944 & 1.853 & 1.764 & 1.678 \\
\hline
\end{tabular}




\section{Conclusions}

Most capability research works appeared in the literatures have not considered gauge measurement errors. Gauge capability has significant effect on process capability measurement. An inaccurate measurement system can thwart the benefits of such endeavors resulting in poor quality. Analyzing process capability without considering gauge capability leads to unreliable decisions. In this paper, we considered the performance of the precision index $\mathrm{C}_{\mathrm{p}}$ with presence of gauge measurement errors. We investigated the accuracy of the estimator $\tilde{\mathrm{C}}_{\mathrm{P}}^{\mathrm{Y}}$ when the sample data is contaminated by random measurement errors. We showed that the confidence coefficients may become insignificant, and that the $\alpha$-risk and the power of the test may decrease with a significant magnitude due to gauge measurement errors, resulting with too understating capability. It could be a serious loss to the producers if gauge capability is not considered in process capability estimation and testing. Improving the gauge measurement and properly training the operators can reduce the measurement errors. Since measurement errors may not be avoided, having proper confidence coefficients and power becomes essential. We also provided adjusted confidence bounds and critical values for practitioners to use in determining whether their processes meet the capability requirement

\section{References}

Chou, Y. M. \& Owen, D. B. (1989). On the distributions of the estimated process capability indices. Communication in Statistics-Theory and Methods, 18: 4549-4560.

Juran, J. M., Gryna, F. M. \& Bingham, R. S. Jr. (1974). Quality Control Handbook. New York: McGraw-Hill.

Kocherlakota, S. (1992). Process capability index: Recent development. Sankya: The Indian Journal of Statistics, 54(B), Pt. 3: 352-369.

Kotz, S. and Johnson, N. L. (1993). Process Capability Indices. London: Chapman \& Hall.

Levinson, W. A. (1995). How good is your gage? Semiconductor International 165-168.

Mandel, J. (1972). Repeatability and reproducibility. Journal of Quality Technology, 4(2): 74-85.

Mittag, H. J. (1997). Measurement error effects on the performance of process capability indices. Frontiers in Statistical Quality Control 5: 195-206.

Mizuno, S. (1988). Company-wide Total Quality Control. Tokyo: Asian Productively Organization.

Montgomery, D. C. (2000). Introduction to Statistical Quality Control, 4th edn. New York: John Wiley and Sons.

Montgomery, D. C. \& Runger, G. C. (1993). Gauge capability and designed experiments. Part I: basic methods. Quality Engineering 6(1): 115-135.

Pearn, W. L., Kotz, S. \& Johnson, N. L. (1992). Distributional and inferential properties of process capability indices. Journal of Quality Technology, 24: 216-231. 